\title{
The Influence of Physical Activity on International Students' Cross-Cultural Adjustment: A Qualitative Longitudinal Study
}

Shuang Li

Follow this and additional works at: https://researchrepository.wvu.edu/etd

\section{Recommended Citation}

$\mathrm{Li}$, Shuang, "The Influence of Physical Activity on International Students' Cross-Cultural Adjustment: A Qualitative Longitudinal Study" (2015). Graduate Theses, Dissertations, and Problem Reports. 6074. https://researchrepository.wvu.edu/etd/6074

This Dissertation is protected by copyright and/or related rights. It has been brought to you by the The Research Repository @ WVU with permission from the rights-holder(s). You are free to use this Dissertation in any way that is permitted by the copyright and related rights legislation that applies to your use. For other uses you must obtain permission from the rights-holder(s) directly, unless additional rights are indicated by a Creative Commons license in the record and/ or on the work itself. This Dissertation has been accepted for inclusion in WVU Graduate Theses, Dissertations, and Problem Reports collection by an authorized administrator of The Research Repository @ WVU.

For more information, please contact researchrepository@mail.wvu.edu. 
The Influence of Physical Activity on International Students' Cross-Cultural Adjustment: A Qualitative Longitudinal Study

\author{
Shuang Li \\ Dissertation submitted \\ to the College of Physical Activity and Sport Sciences \\ at West Virginia University \\ in partial fulfillment of the requirements for the degree of \\ Doctorate of Philosophy in Kinesiology \\ Sport and Exercise Psychology
}

Samuel Zizzi, Ed.D., Chair

Grace Atebe, Ed.D.

Damien Clement, Ph.D., ATC

Monica Leppma, Ph.D.

Jack Watson II, Ph.D.

Department of Sport Sciences

Morgantown, West Virginia

2015

Keywords: International Students, Physical Activity, Cross-cultural Transition, Adjustment Copyright 2015 Shuang Li 


\begin{abstract}
The Influence of Physical Activity on International Students' Cross-Cultural Adjustment: A Qualitative Longitudinal Study
\end{abstract}

\title{
Shuang Li
}

International students face multiple challenges due to cross-cultural transition. Physical activity plays a significant role in maintaining health and well-being for college students. Little research has explored how international students' physical activity interacts with their acculturation. Using a longitudinal qualitative approach with individual interviews and nonparticipant observation, the current study explored how physical activity interacted with new international students' first-year transition to studying in the United States. Nine participants who engaged in regular physical activity were enrolled. Each individual was interviewed twice in the middle and at the end of their first year. Three-month of field work was applied to capture international students' physical activity experience. Data were analyzed using an inductive approach. Results suggested that international students' cross-adjustment occurred academically, socially, and culturally in support of previous research. Physical activity played a role in those areas. Practical implications, limitations, and future research recommendations were discussed. 


\section{Acknowledgments}

This project cannot be done without the help of numerous people. First of all, I would like to express my sincere gratitude to my dissertation chair Dr. Sam Zizzi, who offered me continuous support throughout my Ph.D. study. Without you, I do not know where this project would be. You are the greatest advisor in my eyes. You can be a supportive American professor who has too much belief in me, and a straightforward Chinese professor who gives clear and direct guidance. In the past five years, all the interaction with you is always inspiring, encouraging, and pleasant because of your understanding of me and my culture.

Thank you, Dr. Watson, for supporting me along the way. The pop-up discussion, the chit-chat in the hallway, and the recharging conversation on a Friday night help me a lot. Your door is always open when I need help. Your advice about this research is incredibly beneficial.

Dr. Leppma, thank you for all your support in my dissertation and my counseling. You offered great advice along the way. Thank you for being a part of this project. Every meeting with you was beneficial and enjoyable.

Dr. Clement, I enjoyed working with you in both teaching and dissertation. Thank you for your great advice on my research. Thanks for helping me contact undergraduate students to help with transcribing. Thanks for always encouraging me!

Thank you Dr. Atebe for helping me with my dissertation despite your incredibly busy schedule. Thank you for offering me suggestions from your working experience with international students.

Dr. Malayna Berstein, you are always the first person I would go every time I have questions about qualitative research. Thank you for all the help with methodology!

I take this opportunity to express gratitude to Dr. Dana Brooks. I learned a lot from working with you. I enjoyed your African American Sport class, Sport Sociology class, and doing historical research.

Thank you, Anna and Jay, for helping me with the data analysis. Your input to the analysis and data interpretation is so valuable. Even in the summer, you chose to dedicate your time to help me. I appreciate your time and effort. Jana and Sae-Mi, thank you so much for helping me build connections with international students. I would like to thank all my participants. Without you, I could never finish this project. Thank you for the openness and willingness to share your story, your home culture, and your wisdom with me. Thank you for letting me be part of your exercise. And all my fellow students in the SEP program, thank you for being amazing accompanies. Life is colorful with everybody. 
Running head: INTERNATIONAL STUDENTS’ PHYSICAL ACTIVITY

Finally, to my parents. Thank you for believing in me and all my decisions. Your love and care is always sent via loud and noisy laughs, which made my life easier during the hardest time.

献给我的父亲, 母亲。 
Running head: INTERNATIONAL STUDENTS’ PHYSICAL ACTIVITY

Table of Contents

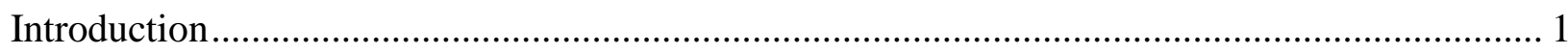

The Challenge of Assimilation .................................................................................... 1

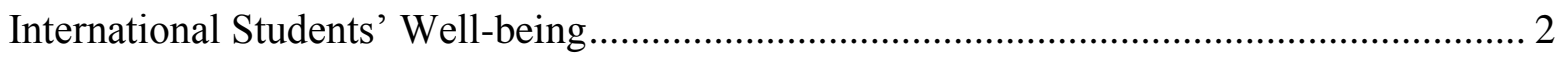

International Students' Physical Activity .................................................................. 3

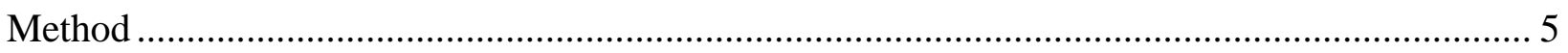

Research Design and Paradigm ......................................................................... 5

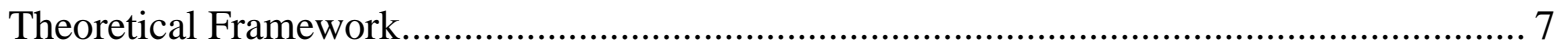

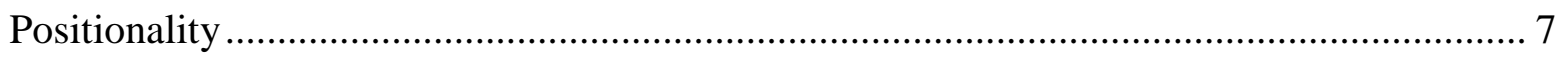

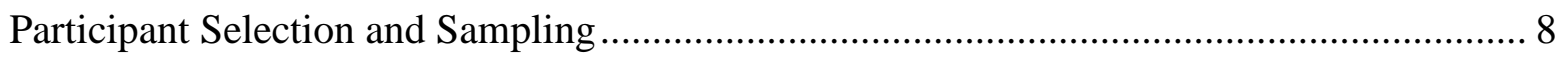

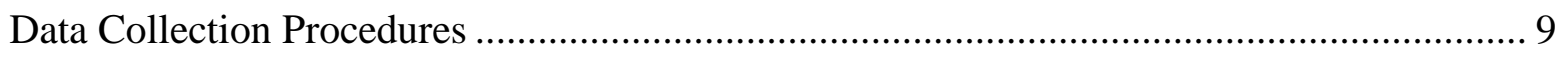

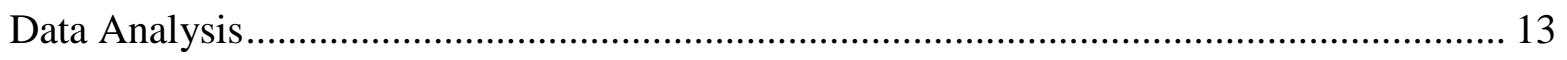

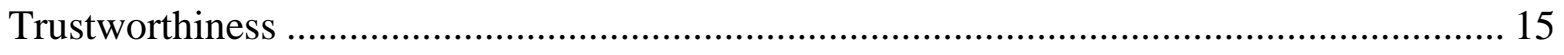

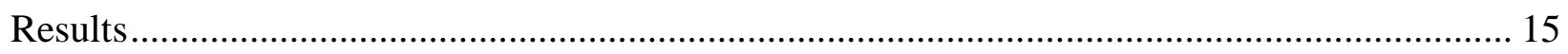

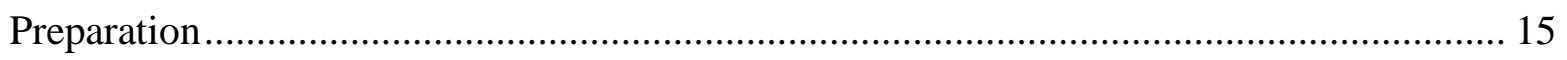

Cross-Cultural Experience in the First Semester.................................................... 17

Academic Transition ...................................................................................... 17

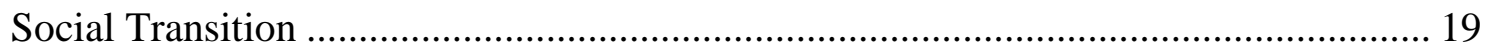

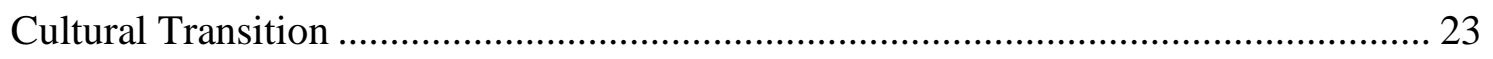

Cross-Cultural Experience in the Second Semester .................................................. 26

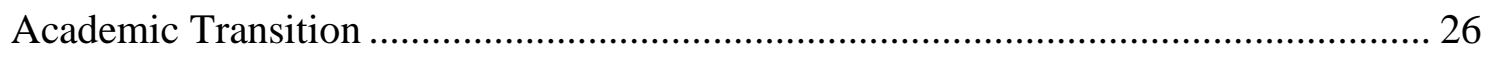

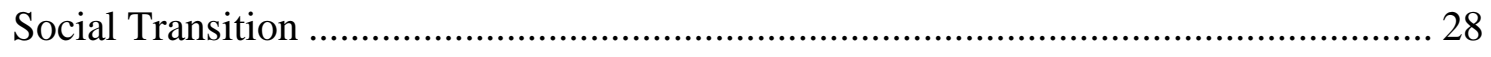

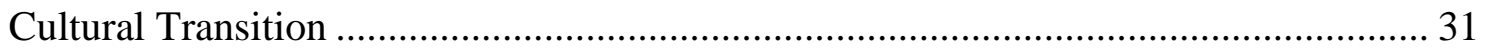

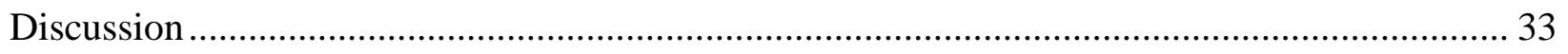


Running head: INTERNATIONAL STUDENTS' PHYSICAL ACTIVITY

How Physical Activity Influenced Cross-Cultural Transition................................................ 35

How Cross-Cultural Transition Influenced (Motivated) International Students' Physical

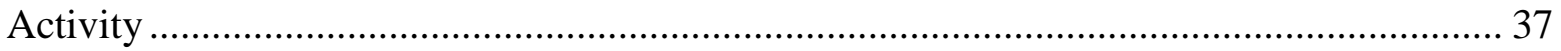

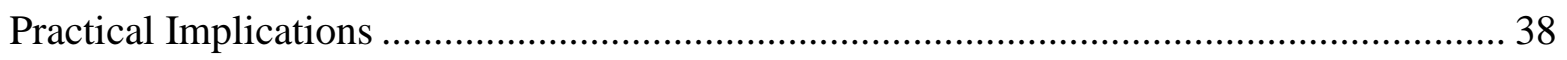

Limitations and Future Research Recommendations ......................................................... 40

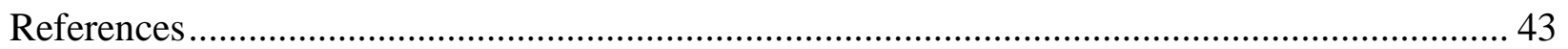

Appendices

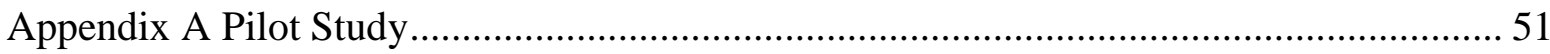

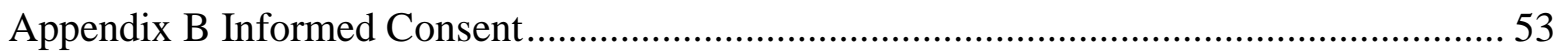

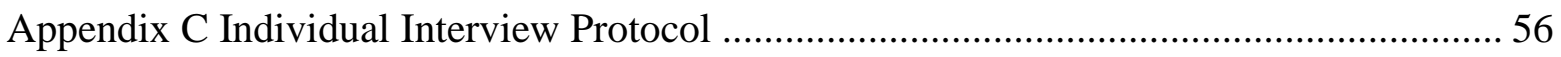

Appendix D Extended Review of the Literature ………….................................................. 58 
Running head: INTERNATIONAL STUDENTS' PHYSICAL ACTIVITY

\section{List of Tables}

Table 1 Participants' Demographic Information 48 
Running head: INTERNATIONAL STUDENTS' PHYSICAL ACTIVITY

\section{List of Figures}

Figure 1 Berry's Acculturation Model and Lopez-Class and Colleagues' Supplement .50 
INTERNATIONAL STUDENTS’ PHYSICAL ACTIVITY

\section{Introduction}

Globalization brings numerous international students to the United States each year. The number of international students has increased $40 \%$ in a decade (Institute of International Student Education, 2013), helping this group become one of the fastest growing populations. Coming to the U.S., international students face multiple challenges due to acculturation, developmental needs, and academic demands. Residing in the U.S., a new culture also brings the assimilation of new ways of thinking and behaving, new outlooks, beliefs, and values.

International students are more than cross-cultural travelers. Specific features within this population should be taken into account while exploring their experiences, adjustment, and psychological outcomes. Like all American students, international students are going through the same developmental challenges; unlike American students, international students encounter unique psychological stressors due to their cross-cultural experiences.

\section{The Challenge of Assimilation}

According to Berry's (1997) acculturation model, individuals entering a new culture will experience plural societies, which may lead to a power difference (majority or the American culture vs. ethnic minority or the home culture). Conflicts might happen depending on the cultural discrepancy (e.g., the difference between the two cultures regarding political system, social structure, economics, values, norms, and attitude), openness of the hosting culture (i.e., attitude toward diversity, stereotype or discrimination, and inclusiveness), individual characteristics (i.e., age, gender, education background, motivation, language, religion, and personality), and coping capacity (i.e., coping skills, available social support) (Berry, 1970, 1980, 1997, 2005, Berry \& Kim, 1988) (see Figure 1). Lopez-Class, Castro, and Ramirez (2011) added a critical point upon Berry's model. These researchers suggested that the local 
INTERNATIONAL STUDENTS' PHYSICAL ACTIVITY

environmental context (i.e., social network, community, and neighborhood resources) should be considered in the process of acculturation. Thus, there is a variability on the psychological consequences of acculturation within the cross-cultural travelers due to multiple levels of factors.

\section{International Students' Well-being}

International students are more than cross-cultural travelers. Specific features within this population should be taken into account while exploring their experiences, adjustment, and psychological consequences. Mori (2000) indicated that most international students chose to live in a foreign academic environment for the purpose of study and they take academics as their primary responsibility; thus, struggles with academics could be especially stress-provoking. Using English as a second language (Duanmu, Li, \& Chen, 2009; Mori, 2000), unfamiliarity with the American educational system and academic culture (Duanmu et al., 2009; Thomas \& Althen, 1989), and juggling multiple roles in their research and teaching pursuits (Mori, 2000) all contribute to academic stress. Lack of social support is another significant challenge international student face during the transition. Social loss (being physically far away from family and friends) (Hayes \& Lin, 1994), loneliness, challenges from developing new roles and rebuilding support system in a new cultural environment can lead to distress in international students. Entering a new environment, international students may experience conflicts in their values system, and adaptive behaviors and skills may not be as effective as in their home culture (Dao, Lee, \& Chang, 2007). Sometimes, international students from Eastern cultures might have to sacrifice some of the core values in their self-identity to socialize (e.g., behaving in an individualistic pattern) (Sawir, Marginson, Deumert, Nyland, \& Ramia, 2008).

International students are a vulnerable population (Sherry, Thomas, \& Chui, 2010).

McLanchlan and Justice (2009) emphasized the needs for more research on international 
INTERNATIONAL STUDENTS' PHYSICAL ACTIVITY

students' and health; these researchers found that the first 6-12 months living in the U.S. was especially challenging and might lead to health related problems. Influences of acculturative stress, social support, and the use of counseling services can interact with each other and create a mixed impact on international students. Lee, Koeske, and Sales (2004) found that acculturative stress and lack of social support contributed to mental health symptoms. Depression can be a mental health issue in this population, based on a sample of Chinese students $(\mathrm{N}=130,116$ participants were graduate students) at a U.S. university. Researchers found that $45 \%$ reported symptoms of depression, and $29 \%$ reported symptoms of anxiety (Han, Han, Luo, Jacobs, \& Jean-Baptiste, 2013); an association was also found between low exercise regimen and a higher prevalence of depression and anxiety symptoms. Although counseling services can bring a positive effect on psychological stress, international students are less likely to seek help (Russell, Thomson, \& Rosenthal, 2008). Based on a sample of 979 international students in Australia, $27.6 \%$ of participants reported that they had needed help. However, $9.8 \%$ of the students visited the counseling center, and $59.5 \%$ of those came for only one visit.

\section{International Students' Physical Activity}

Physical activity can be considered as a coping strategy that international students can use to deal with acculturative stress, as it is known to cause both physical and mental benefits ( Berger, Pargman, \& Weinberg, 2006). Physical activity can also serve as an approach to socialization; it can enhance an individual's capacity to interact with social groups (Milroy, 2010). Sports have been noted as an approach to facilitate the transition and maintaining cultural identity (Allen, Drane, Byon, \& Mohn, 2010). There are multiple levels of barriers international students face to engage in a more active life. Shifman, Moss, D’Andrade, Eichel, and Forrester (2012) suggested that no one to participate with, lack of time, and high self-consciousness in 
INTERNATIONAL STUDENTS' PHYSICAL ACTIVITY

physical activity are the highest perceived barriers limiting international students from

participating in intramural sports. The challenges presented during their transition to the U.S. are another constraint that impacts international students negatively. The specific barriers to communication, unemployment, social alienation, and a sense of hopelessness decreased their time and effort on recreational activities (Taylor \& Doherty, 2005).

Cultural beliefs, norms, and values play a significant role in international students' engagement in physical activity. Pan and Nigg (2011) found that value of physical activity was consistent throughout three populations (Filipino, Hawaiian, and Japanese), but valued in very different ways. Both Hawaiian and Japanese reported physical and mental benefits as their primary concern while Filipino added appearance besides physical and mental benefits. Kanhan (2011) found that beliefs regarding the gender roles, religiosity, and acculturation played a role in physical activity participation among Arab American students. Walker, Jackson, and Deng (2007) found that Chinese students perceived more interpersonal and intrapersonal constraints since physical activity in China has more socializing purposes. Li and Stodolska (2006) found that Chinese students placed more importance on education; leisure time activity was associated with a sense of guilt. Literature also suggests that Asian women are least active among all international students (Suminski, Petosa, Utter, \& Zhang, 2002; Yoh, Yang, \& Gordon, 2008); cultural beliefs of gender role can be a significant barrier to females since physical activity was considered as masculine characteristic.

Currently, the literature describes international students' transition experiences and challenges, acculturation and acculturative stress, and perceived barriers to engaging in physical activity. The question remains, "how does physical activity interact with the cross-cultural transition?" One way to address this issue is to explore experiences and perceptions of the 
INTERNATIONAL STUDENTS' PHYSICAL ACTIVITY

international students who engage in physical activity using qualitative methods. The primary researcher conducted a cross-sectional pilot study of international students' perception of being physically active. Results suggested that cross-cultural transition can influence physical activity both negatively and positively (see Appendix A). Cross-sectional studies often focus on international students' perceptions in general with a retrospective recall; no study takes a close look at what factors effectively motivate international students to engage in physical activity, and how cross-cultural transition interacts with physical activity during transition. The purpose of the current research is to explore the factors that successfully motivate international students to engage in physical activity and how physical activity interacts with international students' firstyear transition to studying in the United States.

\section{Method}

\section{Research Design and Paradigm}

A longitudinal qualitative approach was applied to explore new international students' perception of cross-cultural transition and physical activity. Tracking new international students who are currently experiencing cross-cultural transition and engaging in physical activity offers in-depth and less biased information compared to retrospective and cross-sectional approaches. Both individual interviews and observation were used. Qualitative longitudinal research (QLR) methods allowed the current researcher to return to the interviewees to explore the change over time and generate rich, detailed data about individuals or groups using series of interviews and ethnographic methods (Holland, Thomson, \& Henderson, 2006).

The current study was conducted from a social constructive paradigm. The constructivism approach is based on the philosophical assumption that people construct their understanding of reality, and on their interpretation of their immediate surroundings (Schwandt, 
INTERNATIONAL STUDENTS' PHYSICAL ACTIVITY

2000). In the current study, researcher believed that international students constructed their meaning of acculturation and being physically active depending on their cultural background, the interaction with hosting culture, and the environment. In term of ontology, the researcher believed that the there are multiple realities (or meanings) constructed by international students from diverse cultural backgrounds. In term of epistemology, the researcher believed the researcher and international students co-create the meaning of transition and being physically active, and the researcher influenced the research process. In term of methodology, the researcher believed that the meanings of cross-cultural transition and participating in physical activity should be studied when and where it occurred.

During the process, ethnographic techniques were used to explore international students' physical activity under a social constructivist paradigm. Constructivists favor ethnography because it allowed them to present the multiple realities as shared by the participants and also the alternative interpretations as they emerged from data. Al-Saggaf and Williamson (2006) addressed the difference between the terms "technique" and "method". The former meant the specific procedures that are used to collect or analyze data. The latter meant the general rules that govern the implementation of these procedures. Although the researcher applied ethnographic techniques in a longitudinal qualitative method, certain assumptions and rules of ethnography still influenced the individual interviews and fieldwork. First of all, naturalistic perspective was adopted. The naturalistic perspective emphasizes that the world should be studied in its natural state. In this case, observation occurred in a naturalistic setting where international students exercise and socialize. Secondly, the researcher considered the research processes as reflexive; it was through the researcher's interaction with international students that the meanings of acculturation and being physically active was studied. It was impossible for the researcher to be 
INTERNATIONAL STUDENTS' PHYSICAL ACTIVITY

bias-free about the participants that she studied. The researcher was aware that her background influenced the data collection and results interpretation. The researcher was also a part of her research product.

\section{Theoretical Framework}

This research was based on Berry's acculturation theories (1997) and the supplement raised by Lopez-Class and colleagues (2011). According to Berry's (1997) acculturation model, adjustment, perceived conflicts, and psychological consequence may differ depending on culture, individual characteristics, and coping skills. Lopez-Class and colleagues (2011) suggested the influence of the local environment should be considered in the acculturation process. Combining the two theories, the interaction of the beliefs and values of home culture and American culture, individual's experience of acculturation and perceived stress, personal characteristics, and environmental factors all impacted international students' acculturation. Physical activity might serve as a coping strategy in this process, and facilitate a smooth transition for students. (See Figure 1)

\section{Positionality}

As an international student from China, I made the transition from China to the U.S, experiencing acculturation, challenges due to academics, and cross-cultural adjustment. Majoring in sport and exercise psychology, I became more aware of the benefit of moderate physical activity. As an international student, I'd seen the challenges for international students to engaging in physical activity. Speaking from my own experience, international students face more barriers engaging in physical activity, including taking academics as a primary responsibility, adjusting to the overwhelming changes (regarding academic, environmental, social, and cultural changes), lack of support, and lack of transportation. As a student originally 
INTERNATIONAL STUDENTS' PHYSICAL ACTIVITY

from China, physical activity was not something that I would pay attention to or put effort into.

Physical activity was something naturally happening every day, such as walking or cycling for transportation, taking a walk after dinner with family, or engaging in traditional sports in the morning or the evening for recreational purpose. It was different from the culture of physical activity here.

Looking back at my experience as an international student in the U.S., there was a period that I lived an active lifestyle. It was in my first year. Comparing to my recent life, although I was less familiar with the U.S culture; academic demands was overwhelming due to the language barrier; I had to walk 40 minutes after spending time in student recreational center due to lack of transportation; I could keep active at that time. The main reason was that playing badminton with Chinese friends in the student recreation center was the only opportunity I could talk and share with people from my culture. Although we didn't specifically discuss transition issues, I believed playing badminton helped me go through transition and maintain my Chinese identity in my first year.

\section{Participant Selection and Sampling}

The goal of this study was to capture new international students' initial cross-cultural transition and to explore the role physical activity played in this process. The target population was new international students who were at the initial stage of transition and making crosscultural adaptation. Purposeful sampling was used in the beginning of this study. Eligible participants met two criteria: (1) the international student participated in group or individual exercise at least once per week; and (2) the international student had been living in U.S for less than eight months. To general rich data of making cross-cultural transition, participants recruited experienced greater cultural discrepancy (e.g., participants' home culture had a different political 
INTERNATIONAL STUDENTS' PHYSICAL ACTIVITY

system, social structure, language, values, or beliefs). First, the researcher worked with the office of international students and scholars and the student recreation center to send a recruiting letter to all international students on campus. However, there was no response. Then the researcher used her personal connections (i.e., from being an international student herself) with other international students and snowball sampling to recruit more participants. Nine international students (seven male students and two female students) were enrolled in this study. Five participants were recruited through personal connections; three participants were through snowball sampling (referred by one of the participants in the study); one participant was through social activity. All participants agreed to participate in the whole research project, and nobody declined in the process. All participants were initially contacted through text message. The researcher generally introduced the study and asked if they would like to participate. Once participants agreed to take part in this study, the researcher scheduled a time to meet with participants individually to discuss the details of participation. Six participants were graduate students in majors related to Engineering; one student majored in Mathematics; one student majored in music performance; the last one was a transfer student without a major. Participants were aged $25 \pm 2.78$ years. The oldest participant was 30 years old, and the youngest was 22 . Two participants had 2-3 years of full-time working experience after they finished their master's degree in their home country. One participant had a part-time tutoring job for two years. All the other participants had been students before they came to their current university. (See Table 1 for participants' information).

\section{Data Collection Procedures}

Institutional review board approval was obtained before collecting any of the data in this study. Using QLR, the primary researcher tracked nine new international students' cross-cultural 
INTERNATIONAL STUDENTS' PHYSICAL ACTIVITY

experience and physical activity patterns during their first year. Both individual interviews and observation were used. The first individual interviews took place at the beginning of the spring semester in 2015 (e.g., January or February). Then, the primary researcher participated in international students' physical activity and did nonparticipant/participant observation for approximately three months. At the beginning of summer semester of 2015 (also the end of their first-year), individual interviews were utilized to let participants re-construct the meaning of transition and engaging in physical activity. The second time data collection allowed the researcher to re-visit participants and collect the data regarding their physical activity participation and perception of transition again since the cross-cultural adjustment may not have occurred during their first semester. The second individual interview also provided international students with an opportunity to process their first-year experience while the acculturative stress was reduced.

Individual interviews. Semi-structural individual interviews were used in this study. The primary researcher interviewed all participants following the same interview guide. Active listening skills were used in individual interviews. The researcher reflected on and summarized participants' statements to elicit more explanation and ensure the understanding of international students' perception. In the first interview, general introduction to the current study and confidentiality were offered. Then, each participant signed a consent form. The interviewer started with rapport building questions to facilitate the process (i.e., how is your first semester going?). After that, the interviewer inquired international students' initial perceptions of transition, including their preparation for making the transition, significant events that happened, and their opinion of their transition and acculturation. Their initial experience in physical activity and their perception of engaging in physical activity were inquired, including their physical 
INTERNATIONAL STUDENTS' PHYSICAL ACTIVITY

activity history, current exercising habits, and motivation. In the second interview, each

participant's physical activity experience, motivation, and impact from physical activity were

inquired again. They were also asked to recall and reconstruct the meaning of acculturation and being physically active. (See Interview Guide in Appendix C).

Fieldwork / behavioral observation. After the first individual interview, the researcher contacted each participant to gain permission for observation. If participants' exercise schedule changed on a regular basis, the researcher texted each participant every time before observation. Notes were taken during observation. Sands (2001) suggested that "live with naïve" is one of the principles of taking field notes. The researcher entered the field with an open mind; international students' social interaction and their routine of their physical activity were eventually explored after the first individual interview and observation. During the fieldwork, the researcher focused on international students' exercise behavior, including the sports they played, the related events (i.e., social events after playing), the local environment, performance, intensity, duration, and routine. The social interaction was also the researcher's focus, including friendship and social interactions. Participants were invited to comment on the field notes and offer their perceptions and interpretations during observation or in the second individual interviews.

Nonparticipant observation (The researcher's role was as a complete observer) was primarily used. There were two considerations of this choice. First of all, the researcher could not play the sports that the participants engage in (i.e., soccer, cricket); the limited time did not allow the researcher to learn the sports, play with them, get familiar with all group members, and become an insider. Secondly, the researcher observed multiple exercise groups formed by international students from different cultures. It was unlikely for the researcher to adjust herself and fit into multiple cultures simultaneously. However, there was one group that the researcher 
INTERNATIONAL STUDENTS' PHYSICAL ACTIVITY

observed as a participant observer. Two international female students played badminton. The two participants invited the researcher to their play as well as their social activity. The researcher decided that participant-observation was more appropriate to approach this group.

Non-participant observation took place in Feb, Mar, Apr, and May one time per month (three times observation overall for each participant, approximately two hours each time). The longest observation was approximately two hours and a half, and the shortest was approximately one hour and forty-five minutes. There were seven times of participant observation in Mar, April, and May (two-three hours each time); both physical activity and social activity were observed. Observation took place immediately upon arriving in the field. The researcher usually talked with participants about their life and physical activity before they started to play and after their play. If participants were not available, the researcher talked with them when they took breaks. Notes were taken by speaking into a digital recorder during observation. The researcher completed field notes within 24 hours by listening to the digital notes. The field notes were based on researcher's observation, researcher's interaction with the participants and their team, and the researcher's self-reflection.

Saturation. Saturation was defined as the point that no significant new information emerged through data collection. During the data collection, the researcher noted that participants reported repetitive statements of academic and social adjustment. However, the perception of cultural difference and cultural adjustment varied depending on individuals' previous experiences, family backgrounds, and home culture. Recruiting more participants (i.e., from Europe or Africa) would bring new information to the current data. However, rather than recruiting a large enough sample size to gather all different perspectives of cross-cultural 
INTERNATIONAL STUDENTS' PHYSICAL ACTIVITY

adjustment, the researcher in this project focused on the ongoing interaction between

international students' cross-cultural experiences and physical activity.

There is no universal accepted sample size in qualitative research. Fusch and Ness (2015) suggest that saturation is not about a number. A case study with one single participant can reach saturation by collecting rich and detailed information. A qualitative study with good quality should have "rich" data and "thick" descriptions. Lee, Woo and Mackenzie (2002) claimed that a qualitative study that incorporated more than one method, or multiple interviews with the same participant (i.e., longitudinal) required fewer participants to reach saturation. In the current study, both individual interviews, field notes, as well as the researcher's self-reflection were collected and analyzed. Thus, the data collection researched saturation by multiple data collection methods, two individual interviews on each participant, as well as a large amount of and in-depth information.

\section{Data Analysis}

Currently, there was no systematic or universal way to analyze longitudinal qualitative data. Saldana (2002) suggested that data analysis should be determined depending on the context, and it can be creative. Longitudinal data was complex, it came from multiple sources, and multiple changes could be identified in the analysis. Saldana (2002) suggested that a series of specific questions are needed to assist the researcher when data is collected, reviewed, and coded. In the current study, two questions were used to guide data analysis: (1) What, when, why, on what condition, and how did adaptation happen during transition? (2) How did physical activity interact with transition? Those questions helped the researcher determine the areas that need further exploration. 
INTERNATIONAL STUDENTS' PHYSICAL ACTIVITY

The primary researcher (or a trained transcriber) transcribed the interviews verbatim.

Before data analysis, the researcher compared the transcription with the interview audio to check the accuracy. Then, a research team was developed that included the primary author and two additional researchers trained in qualitative methods. The individual interview data were initially assembled in chronological order and placed in two "pools" before coding. There were two coding cycles. In the first cycle, descriptive coding was used. Descriptive coding was also referred as "topic coding". The researcher chose descriptive coding for two reasons: (1) descriptive coding was particularly useful while analyzing a variety of data forms (in the current study, data included interview transcripts, field notes, and text messages) (Saldana, 2002); (2) due to the language barrier, international students might use incorrect words or phrase, or use body language to help communication, it was more important to identify the major topics they shared rather than scrutinizing the nuances. Before the first cycle, the research team read through the transcripts and assigned topics (codes) to participants' statements. Then the researchers discussed the codes and put them into multiple categories. Based on the categories and codes, the research team assigned a definition to each code and category. If there was a disagreement with the codes, the researchers discussed the codes while looking at the literature in this field until reaching consensus. After that, the research team created a coding book with both codes and explanations and examples for each code. In the first cycle, the research team members coded $44.4 \%$ of individual interviews and field notes (four participants' data) separately based on the coding book that was developed by the team. Then the primary researcher revised the coding book based on the feedback from the separate coding. Since the separate coding revealed high agreement $(82.35 \%)$, the primary researcher finished the remaining coding based on the revised coding book. In the second cycle coding, pattern coding was used. Saldana (2002) suggested that 
INTERNATIONAL STUDENTS' PHYSICAL ACTIVITY

pattern coding could help to develop a statement that described a major theme, a network of interrelationships, and a theoretical construct from data. In the second cycle, the researcher focused on the relationship between physical activity and international students' academic, social, and cultural adjustment. Another experienced qualitative researcher was involved in the second cycle to reduce the primary researcher's biases.

\section{Trustworthiness}

Trustworthiness was established in several ways. Before coding, the primary researcher checked all the transcripts while listening to the audios of the interviews to ensure accuracy. Each transcript was sent to the respective participants for member check. However, no participants replied to the researcher. The data was analyzed in a collaborative way with two other researchers. Before coding, the research team had two meetings to discuss codes and created a coding book with meanings and examples assigned to each code. The collaborative coding revealed high agreement. The lead researcher coded the rest of the transcripts following the coding book. In the second cycle, the discussion with another qualitative researcher who was familiar with this study helped the lead researcher monitor and reduced biases.

\section{Results}

The data from the interviews was divided into three pools: preparation, the first semester (including the Christmas break), and the second semester (including part of the summer time). Multiple factors were identified in each pool. Before the preparation of the following results section, each case study was written up in a standard format. Since the cases might be identifiable, they were not presented in the results.

\section{Preparation}


INTERNATIONAL STUDENTS' PHYSICAL ACTIVITY

Before international students made the cross-cultural transition, they prepared for it in multiple ways. Data analysis suggested that international students prepared for academics, language, life and logistics, and information.

Academics. To be admitted to the U.S. as an international student, all the participants had to prepare for English language tests and graduate entry exams, materials for applying for their programs, and legal documentation for traveling. Besides these themes, two participants spent time reviewing the knowledge they learned from their college. For example, one participant mentioned that "Then, the math, itself. I am already done with my undergraduate school since 2011. So there is a two-year gap between my undergrad and grad school. So re-prepare the Mathematics stuff again.”

Language. The participants who spoke English as their second language spent significant time on language preparation. They took English classes, watched English news and movies, and talked to native English speakers to improve their language. The longest language preparation was two years (2-3 hours per week), and the shortest was two months (intensive English training).

Life and logistics. Preparing for the life and logistics was an important part of this period. Three participants consulted the international students who had been in the university to ask the important things that they need to bring to live here. All the other participants just generally prepared clothes, food, medicine, cooking tools, and other essential personal belongings (i.e., CD, guitar, flag, and favorite Jersey).

To make the transition easier, seven participants mentioned that they collected the information on how to live in the U.S. They consulted the people who had lived in this country and researched the university and the town, to get to know the traditions, rules, the climate, and 
INTERNATIONAL STUDENTS' PHYSICAL ACTIVITY

the local environment. However, all of them suggested that it was a brief conversation or online searching for the information (less than two hours). One participant said that "One month before came here, we have to receive a kind of a two-hour lecture about American culture, something very basic."

Besides that, one participant reported emotional preparation that he might be studying in the U.S. without family and friends, and he prepared for that mentally. All international students scheduled enough time to be ready to study abroad except one participant who had visa issues.

\section{Cross-Cultural Experience in the First Semester}

\section{Academic Transition}

International students came to the U.S. for the purpose of study and meeting the academic demands was their priority. All participants shared their academics in the interviews. Their statements were categorized into three themes: language, academic environment, and academic performance.

Language. Four participants expressed experiencing language barrier in their first semester. Two participants only enrolled in the "Intensive English Program" in the first semester to prepare them for future education. They suggested that they could not understand the class discussion when professors and students were talking fast. Thus, it was difficult for them to respond or engage in class discussion. They also mentioned that they could not speak fluently with professors or classmates. However, listening and speaking in the academic environment was not the most difficult part. One participant mentioned that "I cannot speak clearly, but professors understand..... It is an academic conversation; I am more comfortable with that. I can say there are some pre-defined sentences and conversation, I know what I want to say.” Besides listening and speaking, writing was also challenging for international students. One participant suggested 
INTERNATIONAL STUDENTS' PHYSICAL ACTIVITY

that academic writing was the biggest barrier for him. Participants suggested that they seek opportunities to practice English listening and speaking (i.e., social occasions); however, they were not immediately aware of the available resources to improve their writing.

Academic environment \& performance. All participants found differences in this academic environment comparing to their home countries. Participants suggested that they studied in a diverse environment with professors and students from multiple countries. There was more opportunities, freedom, and flexibility in this environment. It was acceptable to drop a class. Rather than a pre-designed curriculum, they found that they could choose the course depending on advisors' suggestions and their interests. There were also applied opportunities to work on research projects using what they had learned in class. Three participants mentioned that professor-student interaction was more casual (like "friends" and there were "jokes"), and it was easier to speak to the professors. Four participants (they were all from India) found that this academic environment was "stress-free." Oppositely, the other participants were holding different opinions. One participant suggested that it was stressful to have tests frequently. One participant noticed that students here worked hard to get A so that she worked on her assignments or readings every night in her first semester. One participant thought that the grade for a graduate student was extremely important, and there might be a consequence for poor academic performance. He mentioned,

"For graduate students here, the grade is very important. Other people told me. It gives me a big pressure at first. I have to get more than B in each class I take. I thought B is very high grade for me. If you get a $\mathrm{C}$, that will be a big influence to you, maybe you have to go back to your country?" However, all participants were satisfied with their grade. Three participants mentioned that they struggled in one of the classes they were 
INTERNATIONAL STUDENTS' PHYSICAL ACTIVITY

taking. Overall, all participants found that they could meet the academic demands without problems.

Physical activity's role in academic adjustment. International students' priority was to study. Thus, if they found that academics were overwhelming, they tended to meet the academic demands before they engaged in physical activity. One participant suggested,

"(I started to exercise) in October, because for the first two months, I have to get used to the class, I spent a lot of time in class and homework. I was exhausted with homework, so I don't have time and energy."

\section{Social Transition}

Coming into a new environment, one of the challenges international students immediately faced was rebuilding their social circle. In the interviews, all participants shared their social experience in their first semester. Four themes emerged from the data.

Logistical support. International students entered this country and started a new life in an unfamiliar environment, and they brought only luggage. At the beginning of their transition, they were in need of logistical support. All participants reported that they received logistical support (i.e., temporary apartment, ride, free furniture, information, grocery shopping, and help with moving) from the people who had been living here for a while. Six participants only received logistical support from the people or the student association from their countries. For example, one participant mentioned,

"Like Indian Student Association, we contacted them, they helped us with the picking up us from the airport, they gave temporary accommodation, found a room to live, yeah, they helped us, they gave us all important information required for a first year." 
INTERNATIONAL STUDENTS' PHYSICAL ACTIVITY

One participant stayed with a host family in the first couple of months. Her host family helped her with transportation. One participant received the government scholarship from his country, and the scholarship arranged everything for him. Only one participant mentioned that he had American friends, and his American friends gave him rides.

Language barrier in socialization. Five participants had language barrier engaging in social conversations. They reported that American students could understand them even though they had an accent. However, talking in English was challenging since they had a hard time understanding people's conversation. The language barrier influenced more than social interaction. One participant elaborated,

"I also have some speaking problem as right now. It is hard for me to speak with people. You know, it is about my self-confidence..... I cannot hear clearly what others say, and I cannot speak, it narrows my communication...... I was not, comfortable among other students, for example, social events, I just ran away from every crowd. Yes, I don't like to speak more."

Only one participant mentioned that he initialized action to improve his language in social occasions; he went to a church to talk with people even though he was no a church-goer in his home country. He said,

"We take every chance to go out, we went to the church...... It is to find opportunities to talk with foreigners. Not just foreigners, talk with Americans...... Most of them are like me, the newcomers to America, they are from different countries. I think most of them, their intention is to learn English. They (the church) provide English class for different levels. It is useful." 
INTERNATIONAL STUDENTS' PHYSICAL ACTIVITY

Networking and socialization. All participants offered examples of their networking and socialization. They made friends from their department, classes, parties, and the social event in their community (e.g., the "Freshers' Party" organized by Indian Student Association). All the participants suggested that most of their friends were international students, especially the students from their home countries. It was easier to build connection was international students. One participant mentioned,

"If you gather a bunch of American people, you don't really know what they are talking about, it is not interesting to you, and you are talking about is not interested to them, we have a big gap between the way we think, it is different, it is hard to gather together. But basically, if you get used to it, you will find the feeling. But with international students, you have the same issue."

Two of them suggested that they never socialized with people not from his home countries. One participant perceived socialization in this culture as segregated; he said, "You see, Indians stay together in one group. For example, you stay in another group. Americans stay in there. It's not like all together. It's like independent. I never bothered about that. I don't have any American friends or Chinese friends. Sorry, I didn't mean to say that. Like any other friends. I talk with only - I got friends who are Indians only. I never went out with any other person...... I've seen people that aren't interested in other new groups, so that's what I was saying in the beginning. In America, you don't care about the person who is staying beside. It's like they're individualized. That's the reason I was afraid to make new friends."

Three participants shared their socialization with Americans. One of them interacted with Americans in study groups (e.g., joining them doing homework). One participant generally 
INTERNATIONAL STUDENTS' PHYSICAL ACTIVITY

described that he "went along well with everybody". Only one participant had very different experience socializing with Americans. He made American friends from classes and work. He enjoyed and appreciated the interaction with his American friends. He elaborated

"I have like $4-5$ friends, some people were friends from the class, some people we work with the same professor, and some people we work in the same lab..... We sometimes go out for lunch. I take them to the Indian restaurant; they take me to restaurants here. We will have some kind of exchange of cultures, how the Indian food would be. That is really good the way they ask and are excited about the Indian culture. I will usually talk about politics here and there, the conditions, how are things going on here and there. The different kinds of food and stuff. We exchange a lot of different ideas."

Physical activity's role in social adjustment. Physical activity can be considered as a social approach for international students. All participants suggested that they made friends from playing sports. Sometimes, they played with their friends or people they didn't know. Three of them suggested that they never exercised without a friend. In the U.S. culture, socializing in bars or through drinking was common. However, international students might found it uncomfortable. Three participants mentioned that they didn't like socializing in bars or with drinking; one of them suggested that it was against her Muslim culture. One participant also mentioned that he could not understand the jokes while socializing with Americans. Socialization with American students through sports was easier for international students. One participant who played volleyball with both international students and American students said,

"When we play sports, everyone has the same interest. They are talking about volleyball; volleyball is what you are interested. You want to learn. If you learn something, you are happy, you won't be uncomfortable I think..... For example, if you are in a party with 
INTERNATIONAL STUDENTS' PHYSICAL ACTIVITY

Americans, if an American did a stupid thing, they will be laughing, maybe for me, I will think, why you are laughing, he just did a very common thing, why you laugh, because there is a cultural difference. In volleyball, there is no cultural difference."

\section{Cultural Transition}

Living in a new culture, international students found that traditions, habits, beliefs, norms were different from their home countries. They learned the cultural difference from observing other people's behavior. They were also involved in activities that helped them maintaining their cultural identity.

Socio-cultural difference. All participants discussed the socio-cultural difference they learned from the U.S. culture. Six of them suggested that people here were warm-hearted, nice, and respectful to each other. They always said "How are you" and "Have a nice day" and gave a smile to the strangers. Four participants mentioned that they learned to hold the door for the people behind them when they went through a door. International students enjoyed this aspect of the culture. However, four participants held different thoughts. They suggested that although people here were friendly to strangers, the courtesy was superficial. People didn't care about each other in this individualized culture. For example, one participant said,

"I can feel that American people kind of more individual. We heard that in that lecture about American culture. I can feel this. You talked to someone one day, and the other day, the following day or the next week, the person will not be there for you, you will have to look for him or her. I don't know; it is different. We are warmer in Brazil. It is different." Another participant said that "The feeling part is sad of course because you are far away from your home. And also, you don’t feel really warm. Back home, everyone, 
INTERNATIONAL STUDENTS' PHYSICAL ACTIVITY

they care about each other, but here, people don't really care about you, that is why I feel it is so different."

Maintaining cultural identity. International students chose to live in a new environment, and they experienced socio-cultural differences. Thus, it was important for them to navigate the new environment while maintaining their cultural identity. One participant shared her experience of having her first Ramadan in the U.S. and how she kept praying five times a day in both private (e.g., Muslim praying room) and public (e.g., classrooms) places. One participant suggested that he celebrated the Iranian Festival with his community, and he appreciated to see the products belonging to Iran in the shops in this country. One participant reported that the most significant event in the first semester was the celebration of his home culture with the local Indian families; they had traditional Indian shows, songs, and dance.

Environment and food. Living in a new environment, international students found a lot of difference. Six participants mentioned that people in this country were more active than their country of origin. Adjusting to the environment was a challenge. Seven participants suggested that they could not eat the food here so that they cooked with roommates or by themselves almost every day. One participant suggested that he would love to cook the traditional food, but he would not have as many food choices as the dining service offered. Adjusting to the local environment was another task for international students. Six participants suggested that climate here was too cold; it was inconvenient to go out in winter.

Physical activity's role in cultural adjustment. Participants had physical activity in the U.S., and their exercising behaviors were influenced by the local culture and environment. Two participants started to exercise regularly due to the unhealthy eating habit that they developed after coming here (e.g., eating cheap, fast food and ice-cream in Burger King and McDonalds). 
INTERNATIONAL STUDENTS' PHYSICAL ACTIVITY

One participant suggested that he need more exercise because the diet here was less healthy. In a university town without a lot of leisure time activity choices, playing sports became a good option in their spare time. The university town offered a good environment that helped international students' exercise. All participants suggested that the good facilities offered by the university provided them opportunity to exercise. For example, one participant mentioned that his country didn't have the gym like the university recreational center so that students could easily use. One participant said,

"it has great facilities, and the weather does not influence sports." Besides the facility, the informational environment also helped to promote health behaviors; one participant elaborated that "I see all the activities offered to students here, I feel like I should enjoy these...... Here, students are informed by the university. You can see announcements to be offered with many activities, to be healthier."

The socio-cultural difference was also involved in international students' exercising behaviors. One participant suggested that it was easier for girls to exercise in this culture since the Western culture had more freedom than Middle Eastern culture. One participant suggested that he initiated more effort to seek exercise opportunity and played more sports because of the cultural influence. He explained,

"Back in my country, if I see an unknown person, I never ask, "How are you?" or I never smile at them...... I don't say it's wrong, but there's nothing like that....... Here, like it's pretty normal. If you go to a shop, they'll definitely ask you, "How are you?" And they'll say, "Thank you" and "Have a nice day"...... That's one thing I learned a lot...... I never feel comfortable playing with an unknown person there (in my country). But here, yes, I 
INTERNATIONAL STUDENTS' PHYSICAL ACTIVITY

feel really comfortable, because maybe I got adjusted in such a way..... Maybe because of that, I could go to any unknown person, talk with them, I go and play with them."

On the other side, one participant mentioned that the cultural difference hindered his physical activity. He explained that "Americans, you need a very good body, big strength, big muscles, good shape. I want to play basketball, but I cannot, they are too strong to play with. I will get injured." Physical activity was helpful to maintain cultural identity. Four participants reported that a particular sport was considered to be related to their national identity. Playing this particular sport was continuing doing something that they used to do. One participant elaborated "Cricket is a common sport back in my country so in general every day we played cricket, like after school with friends, we almost played cricket every day. Coming here I was happy that there are people here playing cricket and there is a team in West Virginia, and we are like number 14 in the country."

\section{Cross-Cultural Experience in the Second Semester}

\section{Academic Transition}

In the second semester, international students were more used to the academic environment. They started to seek multiple opportunities rather than just focusing on coursework. Data analysis suggested that the language, academic environment, and academic performance were still international students top considerations.

Language. In the second semester, only two participants expressed experiencing the language barrier. One of them suggested that she didn't know how to respond in class since American students talked fast. The other participant found that academic writing was challenging since he was never trained to write a scientific paper in English. Interestingly, these two 
INTERNATIONAL STUDENTS' PHYSICAL ACTIVITY

participants only enrolled in the "Intensive English Program" in the first semester. Thus, the spring semester was their first time to study in an academic major.

Academic environment \& performance. Participants suggested that they adjusted to the academic environment. In the second semester, international students focused more on the issues related to their profession. For example, one participant suggested that professors here taught more techniques while improved students' piano performance rather than just teaching concepts. Another participant suggested that graduate students in the Engineering were expected to do more research, and he would like to spend more time in research in the summer.

Comparing to the first semester that only four students believed the academic culture was "stress-free," all participants in this project suggested that study in the U.S. was not difficult, and they could handle the academic demands. One of them said,

"In my second semester, I am kind of more enjoy, I am kind of lay back in my second semester. In my first semester, I started study so hard, because I was so scary what grade I will have, something like that, because I still didn't adjust this life. In my second semester, I already know the tricks, I can say study here is easy. So I will encourage my friends. Hey, it is easy to go to America and study, come, come to America."

Physical activity's role in academic adjustment. In the second semester, physical activity seemed involved less in international students' academic life. One participant mentioned that her language was improved from playing sports. She explained, "My English gets better because I speak more when we play together. In my department, most of the time, we practice (piano) in separate rooms. I do not have a lot of time to talk with people in my program." Four participants mentioned that physical activity was a good approach to switch focus and relax. For example, one participant had financial struggles in the second semester. He found that exercise 
INTERNATIONAL STUDENTS' PHYSICAL ACTIVITY

was a good way to relax his mind. He said, "Without each other or everything, I might stay at home and think about the stressful thing (finance)."

Observation also suggested that academics involved in international students physical activity. When international students played sports together, they might share the academic challenges they experienced. For example, two participants talked about the assignments and the struggles for their academics (especially before the final week) before they played badminton. Another participant discussed his research in the summer and the plans for applying research assistantship with his soccer team friends; one of his teammate on that day also shared that he failed his Ph.D. qualify yesterday, and he might take one more year for his degree. International students usually took the time to change clothes and shoes and warmed up before they started to play, and they might use that time to talk about the academic challenges they had and support each other.

\section{Social Transition}

In the second semester, international students were more familiar with the environment. They need less logistical support. Only one participant mentioned that his friends gave him rides. Rebuilding the social circle was still an important part of their social transition.

Networking and socialization. All participants talked about their socialization in the second semester. They socialized through dinner parties and sports; socialization had a significant impact in their first year. All of them reported that most of their friends were international students. Two of them only had friends from their country, and the social circle was very limited. Only one participant mentioned that he made one more American friend, and his friend taught him playing tennis. 
INTERNATIONAL STUDENTS' PHYSICAL ACTIVITY

Physical activity's role in social adjustment. Physical activity was involved in international students' social life in several ways. First of all, international students used social media (e.g., WhatsApp) to help organize physical activity. Five participants mentioned that they had WhatsApp soccer, volleyball, badminton, and cricket groups, which helped them schedule and find people to play with. One participant said that "We have a WhatsApp group, whoever is interested we generally add them to that group. We keep updating everything with each other. If you want to play, just ask, is there anyone coming today?"

Secondly, physical activity as a social approach still played a role in international students' second semester. Three participants suggested that they had road trips with their team for cricket competition. The trips were important social time, and they were more connected with their teammates. During the journey, the team players shared cars and hotel rooms; they also traveled and visited multiple places together after their competition. One participant shared his story of experiencing an abusive friendship in the interview. Engaging in sports and a team helped him rebuild the social circle. Thus, his team was his supportive group. He said that "After that thing (the friendship problem) had happened to me, it took a couple of months to get back. I used to play sports with them regularly, but after coming to notice, I stopped playing badminton with them..... Right now, they (the new friends) call me for the dinner. I mean the other people, the good people, they still call me for the dinner, call me for the volleyball match, they call me for if they are going for a drink, now I just want to be with them...... I play cricket on the weekends, if we have a match, we come back, I'll stay in their home, overnight, I sleep with them, come back to my house the next morning, and they make a call, call me for the volleyball match, I go and play." 
INTERNATIONAL STUDENTS' PHYSICAL ACTIVITY

Two participants believed that they became closer through playing badminton in the first year. The analysis of the field notes also suggested that socialization was an essential factor, which contributed to their friendship. Evidence which suggested that their friendship was strengthened included: one girl moved to the same building with the other girl, so that it would be more convenient for them to exercise together; they always left the recreation center together even though one of them didn't play; they always went grocery shopping and take the bus together even though one of them did not need to shop or take a bus. The researcher's participation also suggested that friendship was developed through physical activity. This was the only group that the primary researcher observed as a participant. The researcher entered the field as an outsider. Through the socialization from playing badminton, the researcher became a member of the two participants' social circle. Evidence which suggested that the researcher held a (temporal) membership of this social group included: their exercise schedule changed partly depending on the researcher's availability; one participant consulted with the researcher if she should apply a Ph.D. program; the two participants brought the researcher to their social circle (i.e., dinner party with her friends and roommates); one participant asked the researcher to help with her moving; and the researcher conducted the second interview in one participant's bedroom.

Besides the benefit of rebuilding social circle, another way that physical activity helped with socialization was providing international students with social support. One participant believed his team could be a useful resource for emotional support once he built the connection with his teammates. He explained,

"Whenever I'm in need of something or when I have a question I could ask them..... It's not for me, but if may be for someone. Like, we get benefits or influence like see if I'm 
INTERNATIONAL STUDENTS' PHYSICAL ACTIVITY

sad, if I'm with the team, they unload the sadness that I have, they help me overcome things. It's obviously that influence, if you are sad, and you sit alone in the home or sit alone in the bar, what does it do? Nothing. If you are with the team, if you are sad, they'll ask you the reason. They will support you. They'll try to make you happy or try to overcome the situation."

\section{Cultural Transition}

In the second semester, international students were more adjusted to the culture and the local environment. The statements about cultural transition were much less than the first semester.

Socio-cultural difference. The socio-cultural difference was still a common theme in the second interview. Their perception was similar with the first semester: the people in this county tended to follow the rules, and they were friendly to each other. There was more freedom in this country that people evaluated you by your capacity, not by your ethnicity, values or beliefs.

Environment and food. Only three participants briefly talked about the local environment. They suggested that the cold weather and the snow made it difficult to work. In a small town, there were not a lot of options for leisure time activity.

Physical activity's role in cultural adjustment. Participants still suggested that good facilities (i.e., student rec center) offered by the university contributed to their exercise. For example, one of them said,

"Because we have the equipment there. After every day's work, I can do other activities to relax myself. I found workout is a good way. You can play with yourself, do it on your own schedule. And, anything else. If you don't use it. It is kind of a waste. You already paid for it. I want to go there every day." 
INTERNATIONAL STUDENTS' PHYSICAL ACTIVITY

Two of them mentioned that they appreciated the effort that university made to students' health behavior. For example, one participant suggested that there were a lot of announcements about exercise on campus. One participant mentioned that receiving gift engaged him in more activity. He elaborated,

"I forgot where I got that, but it was for free, should be in the Mountainlair. Like some event happening there, you can get information and a free Frisbee. I know it plays in that way, I saw people playing in the court. I got a free one. When we have a barbecue, I just brought that and played with my friends. We were not good at it. But I know that is the way to play it, and we started to play Frisbee. We are very interested in it now. One of my friends just came back from China, and one thing he brought back is the new Frisbee..... There is a club in the university, playing Frisbee in every weekend and doing some training. I just join it this summer. We haven't had any activity so far." Comparing to the first semester that international students mainly used the facilities and joined the teams on campus, they found more resources in the local environment. For example, one participant mentioned,

"I have been riding a bicycle in China for several years. I love this sport. And here, what make me excited is that, there are many wonderful trails, very very exciting trails here, one is the in the White Park, love that trail so much. Yeah, over this town, that is what I cannot find in China." Another participant elaborated that "We have hiking twice in the spring semester with my friends. We went to the trails. I think one is in Black Water, one was in Spruce Knob..... My friends searched nice place to go to, the location near Morgantown. And he found this Spruce Knob, it is really enjoyable. And we camped and slept there in the night. We did 30 miles in two days. It was fascinating." 
INTERNATIONAL STUDENTS' PHYSICAL ACTIVITY

\section{Discussion}

\section{International Graduate Students' Adjustment}

In the current study, the researcher explored international students' cross-cultural experience in their first year. In the two individual interviews, international students shared their preparation for the transition, the first-semester, and the second-semester experience. The adaptation took place in three main areas: academics, socialization, and culture. Contrary to the previous literature, results suggest that that international students (in the current sample) didn't experience a lot of academic, social, and cultural stress, or negative psychological consequences of their transition. They did not express a high need for psychological support or additional coping skills. Additionally, international students did not report significant academic stress. These findings were different from the previous literature that suggested that language barrier and unfamiliarity contributed to international students' academic stress (Andrade, 2006; Duanmu et al., 2009). Participants only referred it as "different" studying in a new academic environment. All participants suggested that they could handle the academic demands efficiently, especially in the second semester. Only one participant experienced emotional struggles in his first year due to lack of preparation, visa issues, and financial struggles. All the other participants shared their first-year experience in a positive way. Two of them suggested that warmth was missing in this culture. However, they developed and enjoyed their social circle with all the international students.

There are several explanations for why these differences may have been observed in this sample. First of all, international students might not be comfortable in sharing the specific struggles or maladaptation due to social desirability. Misra and Castillo (2004) suggested that it was possible that international students under-reported their stress due to the stigma of showing a 
INTERNATIONAL STUDENTS' PHYSICAL ACTIVITY

problem or weakness. For example, one participant did report experiencing hateful behaviors towards religion and ethnicity in the individual interview. But it took her three times to have enough courage to share the story. It was possible that international students did experience struggles that might cause physical and mental health-related issue but were reluctant to share. Secondly, it was also possible that all participants in the current study had a smooth crosscultural transition, and they truly had no particular struggles to share with the researcher. All participants were from engineering, mathematics, and music performance programs. Comparing to the majors of social science, their majors required less communication with the host culture. Thus, adjusting to the academic environment might be easier. International students usually considered academics as the most important task (Trice, 2007). If they could handle their priority without any problem, their transition could be smooth. Third, the participants of the current study were mainly graduate students. Comparing to undergraduate students who were facing the developmental tasks of establishing self-identity, independence, authority, and career goals, graduate students were more academic and career focused. They were more mature and might have more coping skills. Thus, their cross-cultural transition could be easier than undergraduate students. Moreover, the current sample was a convenience sample. The participants in this particular group were more prepared for the cross-cultural transition than other international students so that they were willing to participate and share with the researcher. It was also possible that because each participant was engaging in regular physical activity, they received social support and other benefits that mitigated the stress of transition. Next, cross-cultural adaption did not have to be a problem, especially in the university with a diverse population. In the current study, the local environment (e.g., the university) was open. Participants could spend significant time with other international students or their community which made them feel more 
INTERNATIONAL STUDENTS' PHYSICAL ACTIVITY

comfortable. Thus, there was no urgency for them to change or sacrifice their original culture or identity to live up to the expectation of the host culture. This finding was consistent with the Lopez-Class's (2011) emphasis on the local environment's influence on acculturation.

The theoretical framework of the current study was Berry's model. Studies in this area focused on dealing with immigrants' mental health-related problems from a clinical perspective. There were other scholars referring adaptation as the "growth-facilitating nature" (Adler, 1987). Adler (1987) suggested that the cross-cultural transition was not a disease to cure, but a journey of profound cross-cultural learning, self-understanding, and change, which lead to personal growth and increased self-awareness. The results of the current study seemed fitting the "Learning/Growth" model better than Berry's "Problematic" model. During the interviews, international students shared that they observed people's behavior pattern and learned from the culture (i.e., they learned to hold the door for the people behind them). They became more aware of the difference between the U.S. and their home country (i.e., people say "How are you" and "Have a nice day" to strangers). Through learning, their language, knowledge, and capacity were developed to handle academic, social and cultural demands.

\section{How Physical Activity Influenced Cross-Cultural Transition}

Physical activity played a role in international students' cross-cultural transition, and it benefitted them in several ways. First of all, participants in this study used physical activity as a coping resource. It helped to switch focus and relax so that they didn't have to feel stressed. It also helped them feel refreshed and energetic so that they could keep healthy and focus on their studies. International students faced acculturative stress, which could be both acute and chronic, and it appears physical activity may have helped to buffer, and cope with, their stress. Research has suggested that exposure to stress can lead to the release of epinephrine norepinephrine, or 
INTERNATIONAL STUDENTS' PHYSICAL ACTIVITY

cortisol, which all inhibit immune function (LaPierriere, Ironson, Antoni, Schneiderman, Klimas, $\&$ Fletcher, 1994). The moderate physical activity could help improve immune function and decrease the progression of the physical disease. There were three hypothesizes explaining the mechanism of how physical activity improved mental health. The monoamine hypothesis suggested that physical activity released monoamines that influenced the brain as antidepressives. The endorphin hypothesis suggested that physical activity contributed to the release of endorphins, which created the sensation of calm and improved mood (Peluso \& Andrade, 2005). The distraction hypothesis suggested that division from unpleasant stimuli could improve mood during and after exercise. Previous literature offered a scientific foundation of using physical activity as a coping strategy.

Secondly, international students used physical activity to build a social network. This finding was consistent with Allen and colleague's study (2010) that sport can be a social vehicle for international students. They knew more friends and became connected with each other from playing sports. They also used their sport team as a supportive group with whom they could share their academic stress as well as emotional struggles. Through social interaction, international students' mood was improved.

Third, physical activity helped international students maintain their cultural identity. In this study, it was found that international students tied particular sport to their country image and expressed their pride in their countries and culture (i.e., Indians play cricket). These findings support work by previous researchers who have established sport as a culturally meaningful activity (Iwasaki \& Bartlett, 2006), with benefits for immigrants' well-being (Kim, Kim, Han, \& Chin, 2015). Results in the current study coincided with previous literature that sport played a significant role in developing and maintaining a national identity (Allen et al., 2010). A similar 
INTERNATIONAL STUDENTS' PHYSICAL ACTIVITY

result was found in Lee's (2005) research which suggested that Korean students might choose Tae Kwon Do as a way of strengthening the ties to their national and cultural background.

A novel finding in the current study was that physical activity facilitated the communication with the host culture. The intercultural communication was considered as a competence that required students to "encode and decode linguistic and nonlinguistic codes and practices to a given cultural or subcultural community" (Kim, 2000, p. 99). For example, international students might need the in-depth knowledge of the local language, historical, social, and cultural background to understand and respond to Americans' jokes. Even if international students were knowledgeable in English, the context information was missing, which might be the reason that they felt confused in class or social occasions. Physical activity, in particular, organized sport games, required less contextual information. All students were familiar with the rules. Thus, there were less language and contextual demands to navigate. Physical activity could be a good start to communicate with the host culture when international students participated in physical activity with American students, as one participant said "there is no cultural difference in volleyball."

\section{How Cross-Cultural Transition Influenced (Motivated) International Students' Physical} Activity

Previous literature focused on exploring the factors inhibiting international students' physical activity. However, there was no evidence to show that removing those barriers would lead to more activity. This study focused on the factors that successfully motivated international students' exercise. It was found that the cross-cultural transition also played a role in it.

First of all, the unhealthy diet motivated international students to do more exercise. Participants suggested that they were aware of the weight gain and the unhealthy diet in this 
INTERNATIONAL STUDENTS' PHYSICAL ACTIVITY

culture after they came here; they need more exercise to keep the balance. In this study, most of the participants still cooked by themselves every day and kept eating the food that they used to have in their home countries. However, international students did make the transition into a “food toxic environment” (Brownell \& Horgen, 2004). The availability of unhealthy food was increased, especially some low price food that was not attainable or affordable in their home countries. The positive aspect was that international students were aware of the toxic environment. The high self-consciousness turned into motivation for physical activity.

Secondly, international students reported that the environment contributed to their physical activity. They had access to better facilities in the university (e.g., the rec center and intramural fields) which they didn't have in their home country. The informational environment was positive that the university consistently posted announcements about healthy behaviors. The gift they received from the events in the university engaged them in a new sport. All participants mentioned that people in this country were more active than their home countries; the atmosphere was positive. All those factors were the facilitators for their physical activity. This result was consistent with the previous literature on built environment and physical activity. Sallis and colleagues (2012) summarized that availability of physical activity facilities was found to be associated with greater physical activity within adult. In the current study, the university community was a distinctive environment, which provided more accessible facilities than the local environment. International students' perception of the environment was also influenced by the perception of their home country. Most of the participants in this study were from developing countries. Living in the U.S., they saw the difference, more opportunities and improvement of facilities, which contributed to their physical activity.

\section{Practical Implications}


INTERNATIONAL STUDENTS' PHYSICAL ACTIVITY

Physical activity benefited international students physically and mentally. It offered them more opportunity to socialize and build their social circle. It also helped international students relax from academic stress. Physical activity could be an excellent venue to communicate with the American culture. By playing sports, their cultural identity was strengthened. Engaging international students in physical activity will benefit their cross-cultural transition. Those results offered a few practical implications for university administrators who work closely with international students. Raising awareness is beneficial. Information about the food, culture, and benefits of physical activity could be provided to international students. New international students always have the orientation before school starts. These meetings can be an opportunity to inform them about the food culture and the benefits of regular physical activity, in addition to the policies and procedures for being an international student.

Secondly, highlighting the strength in this environment (e.g., free gym, trails) could raise the awareness as well as the interest. There are already good facilities in the environment. There are also opportunities for international students to learn a new sport. Highlighting the strength of this culture might increase their interests.

Third, approaching international students through their own community may be more efficient. The results suggested that most international students spent more time socializing with other international students, especially their own community. They might be reluctant to participate in recreational activities organized by the office of international students and scholars or other agencies. However, international students were more comfortable with their own communities. Thus, they might be more likely to participate in the sports events that are organized by their own community. 
INTERNATIONAL STUDENTS' PHYSICAL ACTIVITY

Fourth, organizing sport events that were popular in international students' home countries might also build their motivation. In this study, all physically active students shared their experience in sports. One common theme was that they all participated in the sports that were popular in their home countries (i.e., Brazilian student-soccer, Indian students-cricket, Indonesian student-badminton). One of the reasons they consistently played those sports was because they were familiar with them, and they could play well. Thus, organizing those types of sport events can be helpful to promote more international students to be physically active.

Last, inviting American students to play with international students can help with their cross-cultural adjustment. This study suggested that physical activity facilitated intercultural communication when international students played with American students. Thus, inviting American students to play could benefit both international students and American students. International students would have a more comfortable occasion to communicate with American students and American culture; American students would have more exposure to cultural diversity.

\section{Limitations and Future Research Recommendations}

There were a series of limitations regarding the methodology. Due to the limited time, the research only explored international students' first-year experience. The cross-cultural adjustment was a broad definition. Rather than a distinct phenomenon in a period, it was a lifelong activity to maximize the "fit" to the host culture (Kim, 2001). The cross-cultural adjustment should be a multidimensional and multifaceted process, which lead to the gradual growth of an individual. Their first year was only the initial step of this journey; it was not a full representation of cross-cultural transition. Future research could prolong the duration (i.e., 
INTERNATIONAL STUDENTS' PHYSICAL ACTIVITY

inquire them the meaning of cross-cultural transition in second or the third year) to see how international students adjust to the American culture eventually.

Secondly, although the longitudinal design were less biased than cross-sectional design, the individual interviews still contained retrospective biases. However, the observation and the interaction with participants during observation didn't.

Third, participants in this study engaged in multiple group and individual activities. The researcher only observed one group activity that they engaged in on campus. Thus, this study only captured the influence of team sport participation on acculturation. International students also exercised alone at home, engaged in competitions and other leisure time activity off campus. Thus, there could be more contributions from physical activity than the researcher captured or other activities that helped them adjust to life in the U.S. Weekly email or text messages could be applied in future research to obtain the information about international students' physical activity every week, to better understand their experience in sports.

In the current study, the researcher observed participants physical activity from an outsider perspective, except one group. There were advantages and shortcomings of being an insider and outsider. In the group that researcher observed as an insider, the researcher had more natural interaction with the participants and they were more willing to share, which helped the researcher gained more knowledge about their behavior pattern and social aspects of their life. However, the observation could be too subjective and biased. For example, the researcher focused more on the social interaction of this group comparing to other groups. There might be other significant phenomena within this group that the researcher failed to notice. On the other side, the outsider perspective could be more objective. However, the researcher might not gain a "real" understanding of the cultural background of a particular community. For example, a 
INTERNATIONAL STUDENTS' PHYSICAL ACTIVITY

participant might be hesitant to share his/her frustration of the group sport that he/she participated in due to lack of trust. Future researchers could do more intensive work from an insider perspective while engaging in conversations with the outsiders. This approach could help the researcher generate a more in-depth understanding of international students' life and reduce bias. 
INTERNATIONAL STUDENTS' PHYSICAL ACTIVITY

\section{References}

Adler, P. S. (1987). Culture shock and the cross-cultural learning experience. In L. F. Luce \& E. C. Smith (Eds.), Toward Internationalism: Readings in cross-cultural communication. Cambridge: Newbury.

Allen, J. T., Drane, D. D., Byon, K. K., \& Mohn, R. S. (2010). Sport as a vehicle for socialization and maintenance of cultural identity: International students attending American universities. Sport Management Review, 13, 421-434.

Al-Saggaf, Y., \& Williamson, K. (2006). Doing ethnography from within a constructivist paradigm to explore virtual communities in Saudi Arabia. Qualitative Sociology Review, 2, 5-20.

Andrade, M. S. (2006). International students in English-speaking universities Adjustment factors. Journal of Research in International Education, 5(2), 131-154.

Berger, B. G., Pargman, D., \& Weinberg, R. S. (2006). Foundations of exercise psychology. Bowling Green State University, Fitness Information Technologies: Morgantown, WV.

Berry, J. W. (1970). Marginality, stress and ethnic identification in an acculturated Aboriginal community. Journal of Cross-Cultural Psychology, 1(3): 239-252.

Berry, J. W. (1980). Social and cultural change. Handbook of cross-cultural psychology, 5, 211279.

Berry, J. W. (1997). Immigration, acculturation, and adaptation. Applied Psychology, 46(1), 534.

Berry, J. (2005). Acculturation: Living successfully in two cultures. International Journal of Intercultural Relations, 29, 697-712.

Berry, J. W., \& Kim, U. (1988). Acculturation and mental health. Newbury Park: Sage. 
INTERNATIONAL STUDENTS' PHYSICAL ACTIVITY

Brownell, K. D., \& Horgen, K. B. (2004). Food fight: The inside story of the food industry, America's obesity crisis, and what we can do about it. Chicago: Contemporary books.

Dao, T. K., Lee, D., \& Chang, H. L. (2007). Acculturation level, perceived English fluency, perceived social support level, and depression among Taiwanese international students. College Student Journal, 41(2), 287.

Duanmu, J. L., Li, G., \& Chen, W. (2009). Determinants of international students' academic performance: A comparison between Chinese and other international students. Journal of Studies in International Education. 14(4), 389-405.

Fusch, P. I., \& Ness, L. R. (2015). Are we there yet? Data saturation in qualitative research. The Qualitative Report, 20(9), 1408-1416.

Han, X., Han, X., Luo, Q., Jacobs, S., \& Jean-Baptiste, M. (2013). Report of a mental health survey among Chinese international students at Yale University. Journal of American College Health, 61(1), 1-8.

Hayes, R. L., \& Lin, H. R. (1994). Coming to America: Developing social support systems for international students. Journal of Multicultural Counseling and Development, 22, 7-16.

Holland, J., Thomson, R., \& Henderson, S. (2006). Qualitative longitudinal research: A discussion paper: London South Bank University London.

Institute of International Education. (2013). Open Doors. Retrieved on December 9, 2013 from http://www.iie.org/en/Research-and-Publications/Open-Doors

Iwasaki, Y., \& Bartlett, J. G. (2006). Culturally meaningful leisure as a way of coping with stress among Aboriginal individuals with diabetes. Journal of Leisure Research, 38(3), 321338. 
INTERNATIONAL STUDENTS' PHYSICAL ACTIVITY

Kahan, D. (2011). Arab American college students' physical activity and body composition, Research Quarterly for Exercise and Sport, 82 (1), 118-128.

Kim, J., Kim, M., Han, A., \& Chin, S. (2015). The importance of culturally meaningful activity for health benefits among older Korean immigrant living in the United States. International journal of qualitative studies on health and well-being, 10.

Kim, Y. Y. (2000). Becoming intercultural: An integrative theory of communication and crosscultural adaptation. Sage Publications.

Laperriere, A., Ironson, G., Antoni, M. H., Schneiderman, N., Klimas, N., \& Fletcher, M. A. (1994). Exercise and psychoneuroimmunology. Medicine \& Science in Sports \& Exercise, 26(2), 182-90.

Lee, D. T., Woo, J., \& Mackenzie, A. E. (2002). The cultural context of adjusting to nursing home life Chinese elders' perspectives. The Gerontologist, 42(5), 667-675.

Lee, J., Koeske, G. F., \& Scales, E. (2004). Social support buffering of acculturative stress: a study of mental health symptoms among Korean international students. International Journal of Intercultural Relations, 28, 399-414.

Lee, Y. (2005). A new voice Korean American women in sports. International Review for the Sociology of Sport, 40(4), 481-495.

Li, M. Z. \& Stodolska, M. (2006). Transnationalism, leisure, and Chinese graduate students in the United States. Leisure Sciences, 28, 39-55.

Lopez-Class, M., Castro, F. G., \& Ramirez, A. G. (2011). Conceptions of acculturation: A review and statement of critical issues. Social science \& medicine, 72(9), 1555-1562.

McLachlan, D., \& Justice, J. (2009). A grounded theory of international student well-being. Journal of Theory Construction \& Testing, 13, 27-32. 
INTERNATIONAL STUDENTS' PHYSICAL ACTIVITY

Milroy, J. J. (2010). Behavior, theory and practice: Promoting physical activity among American college students. (Unpublished doctoral dissertation). The University of North Carolina at Greensboro.

Misra, R., \& Castillo, L. G. (2004). Academic stress among college students: Comparison of American and international students. International Journal of Stress Management, 11(2), 132.

Mori, S. C. (2000). Addressing the mental health concerns of international students. Journal of Counseling \& Development, 78(2), 137-144.

Pan, J., \& Nigg, C. (2011). Motivation for physical activity among Hawaiian, Japanese, and Filipino university students in Hawaii. Journal of Applied Sport Psychology. 23, 1-15.

Peluso, M. A. M., \& Andrade, L. H. S. G. d. (2005). Physical activity and mental health: the association between exercise and mood. Clinics, 60(1), 61-70.

Ransford, C. P. (1981). A role for amines in the antidepressant effect of exercise: A review. Medicine and science in sports and exercise, 14(1), 1-10.

Russell, J., Thomson, G., \& Rosenthal, D. (2008). International student use of university health and counselling services. Higher Education, 56(1), 59-75.

Saldaña, J. (2012): The coding manual of qualitative researchers (2. ed.). Sage.

Sallis, J. F., Floyd, M. F., Rodríguez, D. A., \& Saelens, B. E. (2012). Role of built environments in physical activity, obesity, and cardiovascular disease. Circulation, 125(5), 729-737.

Sands, R. (2001). Sport Ethnography. United States: Human Kinetics, Champaign, IL.

Sawir, E., Marginson, S., Deumert, A.,Nyland, C., \& Ramia. (2008). Loneliness and international students: An Australian study. Journal of Studies in International Education, 12(2), 148-180 
INTERNATIONAL STUDENTS' PHYSICAL ACTIVITY

Schwandt, T. A. (2000). Three epistemological stances for qualitative inquiry. Handbook of qualitative research, 2, 189-213.

Sherry, M., Thomas, P., \& Chui, W. H. (2010). International students: A vulnerable student population. Higher Education, 60, 33-46.

Shifman, R., Moss, K., D’Andrade, G., Eichel, J., \& Forrester, S. (2012). A comparison of constraints to participation in intramural sports between international and noninternational students, Recreational Sports Journal, 36(1), 2-12.

Suminski, R. R., Petosa, R., Utter, A. C., \& Zhang, J. J. (2002). Physical activity among ethnically diverse college students. Journal of American College Health, 51(2), 75-80.

Taylor, T., \& Doherty, A. (2005). Adolescent sport, recreation and physical education: experiences of recent arrivals to Canada. Sport Education and Society, 10, 211-238.

Thomas, K., \& Althen, G. (1989). Counseling foreign students. Counseling across cultures, 3, 205-241.

Trice, A. G. (2007). Faculty perspectives regarding graduate international students' isolation from host national students. International Education Journal, 8(1), 108-117

Walker, G. J., Jackson, E. L., \& Deng, J. (2007). Culture and leisure constraints: A comparison of Canadian and mainland Chinese university students. Journal of Leisure Research, 39, 567-590

Yoh, T., Yang, H., \& Gordon, B. (2008). Status of participation in physical activity among international students attending colleges and universities in the United States. College Student Journal, 42(4), 1110-1117. 
INTERNATIONAL STUDENTS' PHYSICAL ACTIVITY

Table 1

Participants' Demographic Information

\begin{tabular}{|c|c|c|c|c|c|c|}
\hline $\begin{array}{l}\text { Participant } \\
\text { Code }\end{array}$ & Gender & Age & Status & Nationality & $\begin{array}{c}\text { Sports that Participants } \\
\text { Engaged }\end{array}$ & $\begin{array}{l}\text { Recruiting } \\
\text { Approach }\end{array}$ \\
\hline A & Male & 27 & Graduate & China & $\begin{array}{l}\text { Volleyball, basketball, } \\
\text { weight training, } \\
\text { badminton, biking, and } \\
\text { fishing }\end{array}$ & $\begin{array}{l}\text { Social } \\
\text { activity }\end{array}$ \\
\hline B & Male & 28 & Graduate & India & $\begin{array}{l}\text { Volleyball, badminton, } \\
\text { and cricket, Ping-Pong }\end{array}$ & $\begin{array}{l}\text { Personal } \\
\text { connections }\end{array}$ \\
\hline $\mathrm{C}$ & Male & 22 & Graduate & India & Cricket, and badminton & $\begin{array}{l}\text { Personal } \\
\text { connections }\end{array}$ \\
\hline $\mathrm{D}$ & Male & 24 & Graduate & India & $\begin{array}{c}\text { Cricket, badminton, } \\
\text { and tennis }\end{array}$ & $\begin{array}{l}\text { Referred by } \\
\text { one } \\
\text { participant }\end{array}$ \\
\hline $\mathrm{E}$ & Male & 22 & Graduate & India & $\begin{array}{c}\text { Cricket, badminton, } \\
\text { and volleyball }\end{array}$ & $\begin{array}{l}\text { Referred by } \\
\text { one } \\
\text { participant }\end{array}$ \\
\hline $\mathrm{F}$ & Male & 30 & Graduate & Iran & $\begin{array}{c}\text { Soccer, weight training } \\
\text { and hiking }\end{array}$ & $\begin{array}{l}\text { Personal } \\
\text { connections }\end{array}$ \\
\hline G & Male & 24 & $\begin{array}{c}\text { Undergraduate/ } \\
\text { Transfer }\end{array}$ & Brazil & Soccer, Basketball & $\begin{array}{l}\text { Personal } \\
\text { connections }\end{array}$ \\
\hline
\end{tabular}


INTERNATIONAL STUDENTS' PHYSICAL ACTIVITY

\begin{tabular}{ccccccc}
\hline $\mathrm{H}$ & Female & 25 & Graduate & Indonesia & Badminton & Referred by \\
& & & & participant \\
I & Female & 23 & Graduate & Thailand & Badminton & Personal \\
& & & & & connections \\
\hline
\end{tabular}

Note. The first sport was the one that the primary research observed. 
INTERNATIONAL STUDENTS' PHYSICAL ACTIVITY

\section{Figure 1}

Berry's Acculturation Model and Lopez-Class and Colleagues' Supplement

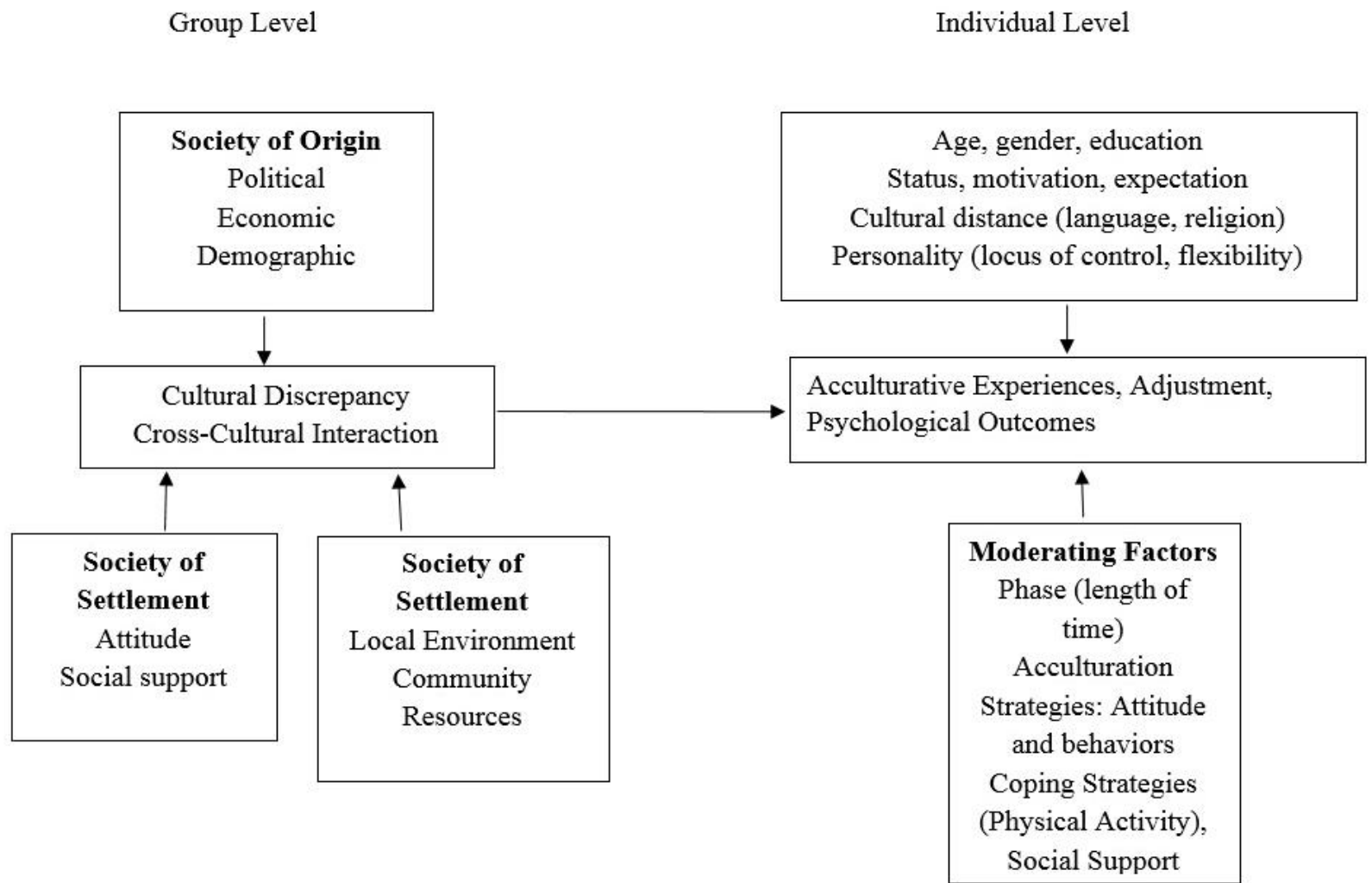


INTERNATIONAL STUDENTS' PHYSICAL ACTIVITY

\section{Appendix A}

\section{Pilot Study}

The primary research conducted a qualitative study exploring international students' perception of being physically active based on a sample of 10 international students (27.70 \pm 4.02 years old from Brazil, Serbia, Spain, Iran, China, France, Russia, Columbia, and Kazakhstan). International students' perception of being physically active, history of engaging in physical activity, and their experience in their home country and in the U.S were inquired through individual interviews in a retrospective approach. Results suggested that transition and acculturation impacted their perceptions of physical activity and exercising behaviors.

International students who engaged in physical activity in the U.S. tied particular sport or activity to their national identity and the history of their home country. The sense of belonging, identity, and pride was associated with engaging in particular activities. Maintaining cultural identity is one of the major challenges of acculturation (Berry, 1980). Thus, engaging in physical activity could facilitate a smooth transition by allowing the student to maintain part of their cultural identity. Another finding in the pilot study was that international students spent more time socializing (or playing) with their own group or other international students; there was limited interaction with American students. Socialization helped them build social networks, and their group could be a resource for emotional support. On the other hand, limited socialization with American students can be a barrier to acculturation and language development. The last significant finding was the perceived difference in physical activity. For example, for a new female international student (had lived in U.S. for four months) from a gender-segregated culture, the "difference" could be both an opportunity and stressor. She reported that physical 
INTERNATIONAL STUDENTS' PHYSICAL ACTIVITY

activity here offered her more freedom, but it was stressful at the beginning since she was not used to exercising around male students.

All results of the pilot study suggested that the influence of physical activity could be both positive and negative. However, the pilot study was limited by a cross-sectional design with retrospective recall. International students' perceptions might be biased. 
INTERNATIONAL STUDENTS' PHYSICAL ACTIVITY

Appendix B

Informed Consent

Only Minimal Risk

Consent Information Form (without HIPAA)

\author{
Principal Investigator Sam Zizzi, Ed.D., Professor \\ Department \\ College of Physical Activity \& Sport Sciences \\ Protocol Number \\ 1411484301
}

Study Title International Students' Participation in Physical Activity and

Perceived Influence on Cross-Cultural Adjustment: A Qualitative Longitudinal Study

Co-Investigator(s)

Shuang Li

Sponsor (if any)

None

\title{
Contact Persons
}

In the event you experience any side effects or injury related to this research, you should contact Dr. Sam Zizzi at (304) 293-0874. (After hours contact: Shuang Li at (304) 906-1305). If you have any questions, concerns, or complaints about this research, you can contact Dr. Sam Zizzi at (304) 293-0874.

For information regarding your rights as a research subject, to discuss problems, concerns, or suggestions related to the research, to obtain information or offer input about the research, contact the Office of Research Integrity \& Compliance at (304) 293-7073.

In addition if you would like to discuss problems, concerns, have suggestions related to research, or would like to offer input about the research, contact the Office of Research Integrity and Compliance at 304-293-7073.

\section{Introduction}

You, , have been asked to participate in this research study, which has been explained to you by Shuang Li. This study is being conducted by Shuang $\mathrm{Li}$ in the Department of College of Physical Activity \& Sport Sciences at West Virginia University.

\section{Purpose(s) of the Study}

The purpose of this study is to explore the factors that successfully motivate international students to engage in physical activity and what acculturative impact is brought on by physical activity during international students' first-year experience.

\section{Description of Procedures}

This study involves two individual interviews, observation, and weekly email in the spring 
INTERNATIONAL STUDENTS' PHYSICAL ACTIVITY

semester, and will take approximately three months for you to complete. You will be asked to participate in two individual interviews: at the beginning and at the end of the spring semester 2015, approximately one hour each. During the Spring semester of 2015, the student researcher (Shuang $\mathrm{Li}$ ) will participate in your physical activity and do observation, approximately twice per month for 30-60 minutes each time. You will also receive weekly email if you exercise at home; this email will include several questions about your physical activity experience in the last week.

\section{Discomforts}

There are no known or expected risks from participating in this study, except for the mild frustration associated with answering the questions related to making cross-cultural transition.

\section{Alternatives}

You do not have to participate in this study. You may choose to discontinue any time in the process. Your class standing will not be affected if you decide not to participate or to discontinue participation.

\section{Benefits}

You may not receive any direct benefit from this study. However, through participating in this study, you will discuss motivation of participating in physical activity in individual interviews, and receive weekly emails about physical activity, you are more likely to live an active lifestyle. The individual interviews also allow you process the significant events of cross-cultural transition. The knowledge gained from this study may eventually benefit international students.

\section{Financial Considerations}

There are no special fees for participating in this study.

\section{Confidentiality}

Any information about you that is obtained as a result of your participation in this research will be kept as confidential as legally possible. Your research records and test results, just like hospital records, may be subpoenaed by court order or may be inspected by the study sponsor or federal regulatory authorities (including the FDA if applicable) without your additional consent.

In addition, there are certain instances where the researcher is legally required to give information to the appropriate authorities. These would include mandatory reporting of infectious diseases, mandatory reporting of information about behavior that is imminently dangerous to your child or to others, such as suicide, child abuse, etc.

Audiotapes or videotapes will be kept locked up and will be destroyed as soon as possible after the research is finished. Only the PI and Co-Investigator will have access to the recording. In any 
INTERNATIONAL STUDENTS' PHYSICAL ACTIVITY

publications that result from this research, neither your name nor any information from which you might be identified will be published without your consent.

\section{Voluntary Participation}

Participation in this study is voluntary. You are free to withdraw your consent to participate in this study at any time.

Refusal to participate or withdrawal will not affect your class standing or grades and will involve no penalty to you. Refusal to participate or withdrawal will not affect your future care, or your student status at West Virginia University.

In the event new information becomes available that may affect your willingness to participate in this study, this information will be given to you so that you can make an informed decision about whether or not to continue your participation.

You have been given the opportunity to ask questions about the research, and you have received answers concerning areas you did not understand.

Upon signing this form, you will receive a copy.

I willingly consent to participate in this research.

Signatures

Signature of Subject

Printed Name

Date Time

The participant has had the opportunity to have questions addressed. The participant willingly agrees to be in the study.

Signature of Investigator or Co-Investigator

Printed Name

Date Time 
INTERNATIONAL STUDENTS' PHYSICAL ACTIVITY

\section{Appendix C}

\section{Individual Interview Protocol}

Section 1 The First Individual Interview

1. What things did you do to prepare for your transition to the U.S?

2. Please describe what your transition to university in the U.S. has been like. Can you think of any significant events that have happened in the first 1-2 months that impacted your transition?

3. What role has physical activity or sport played in your life? Talk first about your physical activity in your home country, and then here in the US.

4. How would you describe your life living in U.S. in the first semester as an international student?

- Prompts: Significant events, perceived differences, barriers, perceptions, feelings, changes, values.

5. Looking into your future, what is your plan regarding to being physically active?

- If the interviewee mentions continuing doing physical activity, the interviewer will ask more about motivation, impact from physical activity.

\section{Section 2 The Second Individual Interview}

1. Besides the sport you are playing, what other physical activity are you doing? What motivates you engaging in physical activity?

- If the interviewee mentions impact physical activity brings to his or her life, the interviewer will ask what types of impact are there, how physical activity impacts life, how physical activity impacts life during the first semester. 
INTERNATIONAL STUDENTS' PHYSICAL ACTIVITY

2. Based on your first-year experience (until now) as an international student, if you were telling a story of your first year experience to your family member or your friend, what is the title of your story? What would you include in this story?

— If the interviewee mentions cross-cultural adjustment, changes, the interviewer will explore their meaning, thoughts, and feeling of making cross-cultural adjustment.

— Prompts: belief, values, behavior pattern changes.

3. Looking back your first-year experience (until now), what role has physical activity played in your life as an international student?

— Prompts: belief, values, behavior pattern changes.

4. What are the reasons of continuing doing physical activity or stopping doing physical activity? What is your plan for the future? 
INTERNATIONAL STUDENTS’ PHYSICAL ACTIVITY

\section{Appendix D}

\section{Extended Review of the Literature \\ Adaption and Acculturation}

Globalization brings numerous international students to the United States. According to the Open Door Report on International Educational Exchange, 819,644 international students came to U.S in 2012-2013 academic year (Institute of International Student Education, 2013); the number of international students increased $40 \%$ in a decade, and the rate of the increase keeps rising in the last three years. International students become one of the fastest growing populations. Coming to the U.S, international students usually face several challenges due to language, transition, adjusting to the new culture, social interaction, academic demands, and homesickness. Numerous studies have been conducted to explore international students' experiences and adjustment.

\section{Theoretical Foundation}

Although concerns with international students are more recent, theoretical models of cross-cultural adaptation and acculturation had been developed based on cross-cultural travelers' experience (e.g., immigrants who went through migration). The knowledge in this area shed light on international students' transition. In the last century, cross-cultural transition theories were developed in the fields of clinical psychology, sociology, and social psychology. The early theories explained intercultural experience from an epidemiological standpoint using medical models. The models from this perspective were based on the assumption that cross-cultural experience is stressful so that immigrants are in need of medical services. The cross-cultural experience was a negative factor affecting individuals' health. Zhou and colleagues (Zhou, Jindal-Snape, Topping, \& Todman, 2008) summarized the historical perspectives of cultural 
INTERNATIONAL STUDENTS' PHYSICAL ACTIVITY

shock and adaptation. The themes from this fields included grief, the locus of control, selective migration expectations, negative life events, lack of social support, social skills and cultural learning.

The more recent models focus on the dynamics of cross-cultural experiences from a social psychological perspective. Acculturation is widely used in social psychology, which is considered as a multi-level process regarding the adaption and cultural change. The definition of acculturation was firstly proposed by Redfield and colleagues in 1936 (Redfield, Linton, \& Herskovits, 1936). It was referred as "those phenomena that result when groups of individuals having different cultures come into continuous first-hand contact, with subsequent changes in the original cultural patterns of either or both groups" (as cited in Berry, 2005). Milton Gordon (1998) also developed a theory addressing immigrants' integration into the host culture. He distinguished the cultural and behavioral assimilation and social structural or institutional assimilation. Graves (1967) firstly divided the acculturation into two levels: collective or group level and individual level. The earlier theories mainly focused on a group of immigrants from a collective perspective while more recent theories explored acculturation on the individual level. Furnham and Bochner (1986) emphasized that learning specific social and cultural skills would help a person engage in a new society. Stress and coping theory developed by Lazarus (Lazarus, \& Folkman 1984) referred cultural adjustment as stressful life events. An individual's cognitive appraisal, coping strategies, and social support can influence the cultural adaptation.

Berry's acculturation theory is one of the most popular models in this area. His model focused on individual's psychological response to the conflicts that are generated from crosscultural experiences. Berry's model is a comprehensive framework, which includes group-level variables, individual characteristics, and moderating factors (Berry, 1997). On the group level, 
INTERNATIONAL STUDENTS' PHYSICAL ACTIVITY

factors regarding a group's biological, social (i.e., political system, social structure), economic, and cultural (i.e., values, norms, attitude) background are included. Acculturation is influenced by the discrepancy between two different cultures. Individual characteristics also play a significant role in acculturation; crucial factors include age, gender, education background, status (e.g., residence or not), motivation, language, religion, and personality (i.e., the locus of control, flexibility). In this process, the moderator can influence the psychological outcomes of acculturation. The possible moderators include the duration of staying in the host culture, coping strategies, social support, and social attitude (i.e., immigrants might have prejudice toward the U.S. culture). Acculturation is a complicated process because not all individuals interacted the same extent with the hosting culture. Berry suggested that there was a high variability on the psychological consequences of acculturation, depending on one's original social and cultural background, personal characteristics, and moderators (Berry, 1970).

According to Berry's model, due to immigration, individual entering a new culture will experience plural societies, which may lead to a power difference (majority or the American culture vs. ethnic minority or the home culture). In this process, two issues will come up: cultural maintenance (maintaining cultural identity, traditions or characteristics that are considered as important to the original culture), and participation (involvement in the host culture). While facing those issues, cross-cultural travelers might use four possible acculturation strategies (Berry, 1997): assimilation, integration, separation, and marginalization depending on individuals' attitude towards acculturation. Assimilation occurs when individuals wish to adopt the dominant host culture and seek daily interaction. Separation occurs when individuals place more value on home culture and avoid interaction with the host culture. Interaction happens when individuals maintain the home culture as well as seek interaction with the host culture as an 
INTERNATIONAL STUDENTS' PHYSICAL ACTIVITY

integral part of the social network. Marginalization occurs when individuals lose interests to both original and host culture. Berry (1997) suggested that the cross-cultural adaption can be both positive and negative. It should be noted that acculturation is an active process. An individual's experience and strategies can be influenced by his/her preference. Berry (1980) suggested that two issues need to be considered in acculturation: the preference of maintaining the home culture and identity, and the preference for having contact with the hosting society and culture.

Meanwhile, acculturation is mutual (Berry, 2005) and individual's preferences could be limited depending on a society's openness (Berry, 1997). Berry's model is based on the assumption that individuals have choices whether to acculturate or not. However, the dominant group might enforce individuals to engage in acculturation when a society or culture is not open to diversity. In this case, people might result in marginalization rather than assimilation when they are facing stereotype or discrimination. It is also possible that they withdraw from acculturation and avoid cross-cultural interaction, or even acquire more stereotypes and prejudice (Berry, 2005). There are more choices in a "free" culture when dominant groups show openness and inclusiveness to multicultural perspectives.

Mental health concerns are addressed by Berry's model from a clinical standpoint. Psychological outcomes of acculturation are affected by the different levels of acculturative difficulty. Acculturation is considered as a process of learning social and behavioral norms of a new culture when there is only moderate "culture conflict." In this case, making psychological and behavioral changes is easy to achieve. When individuals encounter greater levels of conflict, acculturation can be stressful, problematic, but still controllable. In this scenario, acculturative stress might happen. When severe conflicts occur, making changes to adjust to the new culture exceeded one's coping capacity, psychopathology (mental health issues such as depression, 
INTERNATIONAL STUDENTS' PHYSICAL ACTIVITY

anxiety) may set in depending on the context (i.e. magnitude, time limitation) (Berry \& Kim, 1988). Moderators play a role in this process as well. The coping capacity can influence immigrants' mental health. In acculturation, individuals might experience stress, they might use coping skills and social support, and eventually make changes and adapt to the new culture.

\section{Evidence of Acculturation}

Based on the cross-cultural transition models, scholars conducted studies to explore cross-cultural travelers' experiences. The evidence is complicated and inconsistent. Results varied depending on different theoretical models, instruments, populations, and individual difference.

Finch and Vega (2003) explored Latinos' acculturation, stress, and social support. 3012 participants (age from 18 to 59) were selected from Fresno County, California through probabilistic, stratified, multistage cluster sampling. Self-report questionnaires (both in English and Spanish) were sent to participants. Demographic information (including gender, income, and education), health status, whether or not seeing a doctor regularly, whether or not they have insurance, English usage, and the duration in the U.S. were collected. Acculturation, social support, and health were measured. Based on the self-report, participants were divided into two groups: fair/poor health (33.7\%) vs. excellent/very good/good (66.3\%). Data was analyzed through logistic regression. Results suggested that more education, higher income, and being male was related to better health. By putting acculturation stress and social support together (15 variables), only two variables were significant (discrimination, and instrumental support, which refers to having someone who will loan you money, offer a ride or comfort, and if there were family members or friends in the U.S). Instrumental social support only provided health protection to the individuals who were experiencing moderate or high level of discrimination. 
INTERNATIONAL STUDENTS' PHYSICAL ACTIVITY

Discrimination might only harm people who were lacking social support. Religious support reduced the negative effect of discrimination. This study supported the hypothesis that social support had a positive impact on individual health. Religion was considered as an important factor for Mexican adults and contributed to their health. Legal status had significant effects on physical health as well.

By putting empirical studies together, researchers reviewed the acculturation process and outcomes of acculturation based on immigrants from multiple backgrounds. The results in this field are mixed. Lopez-Class, Castro, and Ramirez (2011) reviewed the studies of acculturation based on Latino population. It offered critical points upon Berry's acculturation model. The authors suggested that the local environment or the context (i.e. social network, community, and neighborhood resources) should be considered in the process of acculturation. Salant and Lauderdale (2003) reviewed the acculturation, physical and mental health, and health service use based on studies of the Asian population. 67 studies were identified that addressed the health outcomes of Asian immigrants in the U.S, Canada, Australia, New Zealand, and the U.K. Results suggested that previous studies supported Berry's model that language difficulty, discrimination, value conflicts, and social isolation represented acculturative level, which in turn affected one's acculturative stress. However, the connection between acculturative stress and health was inconsistent. Although research supported Berry's model, there were still factors that were missing but may influence stress and health, such as issues happened in immigration, local community immigrants living in, and different conceptualization of illness.

The two reviews both suggested that the local community that the cross-cultural travelers reside in should be considered. This point can be used exploring international students' transition. International students stay in the universities, which are a unique environment. Thus, 
INTERNATIONAL STUDENTS' PHYSICAL ACTIVITY

international students' cross-cultural transition, adaptation, and the extent of intercultural

communication may be influenced by the local environment (e.g. the universities that they study in).

\section{Where is Stress From? Challenges International Students Experience}

International students is a heterogeneous population, even though they all travel to a different country for the purpose of education. In the current study, the author only focused on the international students who were admitted to the U.S colleges and universities. Comparing to immigrants, they do share similar components of acculturation, including language barriers, cultural discrepancy, and individual characteristics. Moreover, specific features within this population should be taken into account while exploring international students' process and outcomes of acculturation. Like all American students, international students are going through the same developmental stage (i.e., developing self-identity, authority, and social network) (Erickson, 1963). Unlike American students, international students encounter unique psychological stressors depending on their languages, educational and family background, original culture, ethnicity, gender, and graduate status. Wang (2003) summarized the unique problems that international student might encounter in academics in his dissertation. The possible problems included adjusting to the academic culture, adjusting to the different academic community, using English for academic purposes, assuming teaching or research assistant roles, as well as dealing with daily hassles (i.e., health problems, and coping with the new environment). The cultural difference also played a role in international students' adjustment, such as different value systems and behavioral norms, communication barriers, missing signs and cues, and relationship issues.

\section{Academic Demands}


INTERNATIONAL STUDENTS' PHYSICAL ACTIVITY

Meeting academic demands is one of the most significant challenges that international students face. Mori (2000) indicated that most international students chose to live in a foreign academic environment for the purpose of study. They take academics as their primary responsibility. It is very likely that international students might experience more mental pressure from meeting academic demands. Thus, struggles with academics could be especially "stressprovoking". However, findings regarding international students' academic concerns are inconsistent. For example, Misra and Castillo (2004) compared the perceived academic stress and the reaction to academic stressors between American students $(\mathrm{N}=249)$ and international students ( $\mathrm{N}=143)$. In contrary to the researchers' expectations, American students reported a higher level of self-imposed academic stress and behavioral, emotional, and psychological reactions to stressors. Misra and Castillo (2004) explained that it is possible that international students under-reported their stress due to the stigma of showing problem or weaknesses.

The language barrier plays a significant role in adjusting to a new academic environment. Language adjustment is considered as one of the most significant stressors for international students whose first language is not English. Duanmu, Li, and Chen (2009) found that English proficiency is one of the factors that can predict international students' academic performance. Although international students might be required to take the Test of English as a Foreign Language (TOEFL) to be admitted into American colleges or universities, it does not ensure their comprehension, communication, or writing capability in an English-speaking environment. The language barrier places pressure on international students' academics; it negatively influences their ability to understand lectures, take notes, memorize key points, and complete essential readings and assignments (Mori, 2000). Ramsay, Barker, and Jones (1999) also found that international students at an Australian university struggled with understanding the lecture 
INTERNATIONAL STUDENTS' PHYSICAL ACTIVITY

due to vocabulary and speaking speed. Moreover, limited language skills can also strongly influence their performance in class activities, such as group discussions, conveying their thoughts, asking questions, or giving presentations (Kim, 2011). Struggling with language could lead to decreased self-confidence; international students reported that the language barrier and anxiety associated with language barrier prevented them from engaging in discussion or other activities in class (Duanmu et al., 2009).

Although researchers address the challenge of language adjustment, the language barrier is more complicated than merely using English as a second language. Most of the studies only recognized that international students struggle with speaking, writing, comprehension, and memorizing in English. However, individual characteristics and cultural influence should not be ignored while considering the language barrier. Individuals' psychological and emotional stress, such as homesickness, isolation, shyness, anxiety, self-critical thoughts, and lack of confidence can be detrimental to international students' verbal communication, socialization, and academic performance. For example, a particular culture and educational background can shape people's thinking and behaviors. The eastern culture values being humble rather than showing confidence; being quiet, reserve, and non-assertive rather than showing competitiveness; tending to agree with professors and peers rather than pointing out different opinions, debating, or confrontation; following professor's instruction rather than being creative. However, American professors fail to recognize the complexity (Andrade, 2006). Thus, language barrier plus misunderstanding can be especially stressful for international students.

Besides the language barrier, unfamiliarity with the American educational system and academic culture can be considered as an important factor associated with academic stress (Duanmu et al., 2009; Thomas \& Althen, 1989). Adjusting to a new academic culture is essential 
INTERNATIONAL STUDENTS' PHYSICAL ACTIVITY

for international students' academic performance. International students from a different culture are unfamiliar with the expectations, norms, rules, or regulations in American educational environment (Andrade, 2006). The practical experience could be confusing to international students as well since they are not familiar with the supervision and communication style as well as the student-supervisor relationship. For example, Duanmu and colleagues (2009) listed several factors that inhibited Chinese student adjusting to the new educational environment. The study habits that they developed from Chinese culture had negatively influenced their academic adjustment. For example, Chinese culture placed more emphasis on effort (working hard vs. working smart); Chinese students found it challenging with independent learning and less supervision; Chinese students were expected to listen rather than actively participate in class activities. Because of unfamiliarity with the unspoken rules and expectations, professors and students had different perspectives of adjustment. It was found that international students attributed their lack of participation in class to limited language ability while their professors attributed to lack of involvement. Regarding the independent learning and minimum supervision, international students might consider that the professors were indifferent while the professors believed that international students should be more responsible for their learning (Andrade, 2006).

Chen (1999) offered several examples of the relationship between stress and academic performance due to unfamiliarity with North American educational style. International students might consider class presentation as a threat because of the language barrier. Meanwhile, presentations needed more experiences, imagination, and creativity, which international students might never have had an opportunity to develop. The relationship with professors can be another example of being unfamiliar with the academic environment. In Asian culture, there supposed to 
INTERNATIONAL STUDENTS' PHYSICAL ACTIVITY

be a distance between professors and students, and the rigid rules in classrooms (i.e., no eating or drinking in class). All those factors can distract or confuse Asian students.

Language barriers and unfamiliarity with American educational system can be especially stressful for the international students who work with American undergraduate students as teaching/research assistants. Due to poor communication and unfamiliarity with the roles as teaching or research assistants, international students might have more struggles of gaining acceptance, trust, and respect from American students (Mori, 2000).

\section{Social Isolation and Social Support}

Lack of social support and social isolation is considered one of the biggest challenges that international students face. However, multiple explanations are offered by different studies regarding "why" and "how" social isolation influenced international students.

Hayes and Lin (1994) used "social loss" to describe international students' social experience, since they are physically far away from family and friends, and they face double challenges regarding dealing with loneliness and developing new roles and rebuilding support system. Hayes and Lin (1994) also analyzed the factors associated with social adjustment. They found that multiple factors were crucial for international students' social adjustment, including individual difference (i.e. personality, self-esteem, self-confidence), gender roles, stigma (prejudice of establishing a relationship), and language barriers.

Building social support is a challenge for international students. In a qualitative study conducted in the U.K, international students reported that the nature of the relationship with people in the U.K was superficial. They felt alone, isolated, marginalized, intrusive, and excluded. The reason offered by international students included insensitivity to different living habits and unfamiliarity with campus subculture (e.g., drinking alcohol or pub culture) (Bradley, 
INTERNATIONAL STUDENTS' PHYSICAL ACTIVITY

2000). Making an effort in socialization can be another stressor for international students since they were not familiar with the living habits and subculture. In this research, international students suggested that the on-going support from staff or an advisor who had more cultural awareness training were helpful.

Trice (2007) summarized the reason why international students were isolated from their domestic peers based on previous literature. First of all, international students chose not to build the relationship with domestic students due to lack of time, since their academics were their priority. Secondly, it seemed that international students had little interest in establishing the relationship with local students due to the "vast cultural difference." Previous studies found that international students were more likely to have relationships with domestic students when they need actual help (e.g., help with language, need rides). Because of cultural barriers, it was difficult for international students to build a meaningful relationship with their domestic peers. In this study, Trice (2007) also gathered faculty's perceives of the isolation that international students experienced. 27 faculty members were interviewed in this study, including 12 foreignborn faculty and 15 American-born faculty. Interview questions included the extent international students were academically and socially integrated into their department and the reason for isolation. The author also compared the narration between foreign-born and native-born faculty members. Results suggested that both foreign-born and native-born faculty members attributed the reason of isolation to international students because they always had strong bonds with culturally similar students. Language barrier, fewer opportunities working with local professors or students, lack of time, and American students' preference (e.g., American students were less interested in becoming friends with international students) were the factors contributing to social isolation. Although it was not reported by participants, Trice suggested the cultural norms could 
INTERNATIONAL STUDENTS' PHYSICAL ACTIVITY

influence social isolation. International students had different assumptions about meaningful relationships. Compared to the collective culture, the individual culture may seem cold and aloof. Thus, international students might believe that American students were less interested being friends with international students or even considered that there was discrimination. From this perspective, building a relationship with culturally similar individuals could be much easier for international students.

Sawir and colleagues (2008) used Weiss's theory to define and analyze loneliness. Weiss's theory suggested that loneliness had two levels: social (lack of engaging in a social network) and personal (loss or lack of a real intimate tie with significant others). Sawir and colleagues (2008) proposed a third level of loneliness: the institutional sites of loneliness, which refers to the lack of exchange in the classroom, or with professors, university administrators, or other authorities. They conducted a qualitative study in Australia by interviewing 200 international students from more than 30 different nations (most were Asians). 130 students (65\%) expressed concerns about loneliness. The findings were coincident with previous literature that international students had barriers to developing relationships in a new culture. Possible barriers included communication barrier due to language difficulty, lack of understanding, and individual personality (i.e. being shy, introverted). However, results suggested that there was no simple relationship between loneliness and isolation. The social network was desirable. But having an enjoyable social network did not rule out loneliness; the absence of a social network did not necessarily lead to loneliness. The authors suggested that the most important variable in this relationship was the content, especially the cultural content. While the cultural content was missing, internationals student might experience loneliness. This study also pointed out that family was not an adequate emotional support for international students since they did not want 
INTERNATIONAL STUDENTS' PHYSICAL ACTIVITY

their parents to worry too much. For students who didn't report loneliness, reasons included having family in Australia, easily making friends from their own culture, and ignoring loneliness because of being busy.

\section{Financial Challenge}

The financial challenge is one of the most critical issues for international students. Although it is not due to the transition, without adequate financial resources, survival can be a problem. Any breakdown or disturbance can immediately threaten international students' education as well as their living. Although there were a lot of literature specifically looking at international students' finance in the field of cross-cultural transition, the financial challenge can be especially stressful for international students. For example, an early study found that international students ranked financial difficulties as the greatest problem (Klineberg \& Hull, 1979). Sam (2001) examined the factors that could influence international students' life satisfaction. 301 (159 males and 145 females) participants were recruited in the study. The results of the questionnaire investigation suggested that financial situation was the most important factor that could influence all international students' life satisfaction, especially for the students from Developing countries.

\section{Values, Beliefs, and Identity}

Individuals entering a new environment are facing social and cultural difference; they might find that norms, values, and expectations are different. Adaptive behaviors and skills are not as effective as in their home culture (Dao, Lee, \& Chang, 2007). International students transfer to a new society and culture with different norms and expectations. It is possible that they experience conflicts in their values system since the new beliefs are not congruent to their original culture. In this process, frustrations and disorientation can be generated. 
INTERNATIONAL STUDENTS' PHYSICAL ACTIVITY

From a general understanding, value system plays a significant role in international students' transition. However, it is hard to identify studies only focusing on beliefs and values. Belief and value system directly or indirectly influence every aspect of international students' experiences and statements. Culture and values are mostly used to explain international students' struggles and frustrations. For example, international students take academics as their priority, and they place a high value on academic performance. Challenges in academics can be particularly stressful. The value difference can explain this result. Chen (1999) suggested that international students are more likely to feel confident adjusting to a new culture and environment if they perceive they succeed in academics. It was possible that getting a $\mathrm{B}$ or $\mathrm{C}$ is considered as a threat for international students since they have a different belief over the grade. Due to the different dynamics of family, academic performance can be a family concern rather than an individual issue for international students (Chen, 1999). Low self-esteem or feelings such as frustration, depression, and guilt can be generated.

Sawir and colleagues (2008) analyzed international students' loneliness. They suggested values and beliefs played a significant role in social isolation. International students might have to sacrifice some of the core values in their self-identity to adjust to the new culture. The host environment or the host culture will not change to meet international students' needs. The adjustment is more like a "one-way" process. International students have to initiate the change to fit in the host culture. As pointed out by the authors, an international student might have to spend individual, economic, and cultural cost for socialization. For example, going to a bar to drink to fit in a social group, behaving in the individualistic pattern they do not have belief in (i.e. being competitive rather than being humble, being confrontational rather than following others' thoughts). This explanation can be tied to Trice's study (Trice, 2007). It is not that international 
INTERNATIONAL STUDENTS' PHYSICAL ACTIVITY

students are not interested in building a relationship with domestic students; it is that they have to pay too much to build the social network with their local peers.

Considering all challenges international students might encounter, there is a connection between cross-cultural adjustment and stress. However, while exploring international students' experience of socialization, acculturation as well as acculturative stress, beliefs and values should be considered.

\section{Acculturation, Using University Services, and International Students' Health}

Because international students are facing multiple challenges due to transition, more attention should be placed in this population. International students are a vulnerable population (Sherry, Thomas, \& Chui, 2010). McLanchlan and Justice (2009) emphasized that more research should be done to address international students' concerns. It was found that the first 6-12 months living in the U.S was especially challenging for international students and might lead to health problems. Based on a sample of Chinese students ( $\mathrm{N}=130,116$ were graduate students) at a U.S. university, researchers found that $45 \%$ reported symptoms of depression, and $29 \%$ reported symptoms of anxiety (Han, Han, Luo, Jacobs, \& Jean-Baptiste, 2013).

International students' health concerns can be complicated. Besides acculturative stress, many factors could influence an individual's health. Capturing health through a snapshot might not fully reflect international students' health. Salant and Lauderdale (2003) suggested that single measurement of physical or mental health can be problematic. Moreover, based on Berry's model, there is not a simple relationship between acculturation and health. Moderators play a significant role in this connection. Thus, a lot of studies of international students' health combine transition, needs, and the usage of counseling service and health professionals. 
INTERNATIONAL STUDENTS' PHYSICAL ACTIVITY

Bradley (2000) explored international students' mental health needs in England using a qualitative approach. He conducted two focus groups (international students and domestic students). They were asked the same questions, to compare the perceptions between international students and local students. It was found that two groups did share similar factors, such as relationship issues and financial burden. However, several unique factors were reported by international students. For example, the nature of the relationship with English friends was always "superficial" and international students felt alone and isolated. Different life habits, academic pressure due to language, different teaching style, loss of control, and financial insecurity contributed to health problems.

Lee, Koeske, and Scales (2004) conducted a study to explore Korean international students' acculturative stress, mental health, and social support. 74 Korean international students were recruited from a university in the U.S. The Index of Life Stress (ILS) was used to measure acculturative stress. The Brief Symptom Inventory was used to examine their psychological distress as well. The support resources were measured by a direct instrument developed by the current authors. Suinn-Lew Asian Self-Identity was used to measure the acculturation. Results suggested that acculturative stress was related to lower levels of acculturation. Acculturative stress was a strong predictor of mental health symptoms. Social support played a significant role in this relationship. Even if Korean international students had acculturative stress, high levels of social support could reduce mental health symptoms.

In a study conducted in Australia (Russell, Thomson, \& Rosenthal, 2008), researchers investigated 979 international students in a university, to explore international students' wellbeing and the use of counseling service. It was found that $41.2 \%$ of participants reported they needed help. However, only $62.2 \%$ of those participants who were in need of help actually 
INTERNATIONAL STUDENTS' PHYSICAL ACTIVITY

sought help; $47.8 \%$ of students who sought help only made a single visit while $42.2 \%$ made two or three visits. It was also found that there was a significant difference between Asian and NonAsian students over help-seeking behaviors. Students from Asia were less likely to perceive the need of seeking help or the need for taking action based on their needs.

International students were reluctant to use counseling service in universities because counseling might have other meanings in their belief system. For example, Chinese refer mental illness to physical problems, such as "nerves" or a headache. Rather than seeking counseling services, it was more likely for them to go to a physician for treatment (Han et al., 2013).

Based on the previous discussion, it can be seen that international students face multiple challenges and acculturative stress. Acculturation requires effort and can add distress. However, they are less open to counseling. Thus, exploring effective ways to facilitate international students in their transition and adjustment is essential to help them live successfully in a new society and culture.

\section{International Students and Physical Activity}

Physical activities (PA) are found to be both physically and mentally beneficial. Increasing physical activity could lead to additional improvement in one's health status (Dishman, Washburn, \& Heath, 2004) and reduce the risk of all-cause and cardiovascular-related death, diabetes, cancer, and premature death from obesity or cardiovascular disease (Warburton, Nicol, \& Bredin, 2006; Pender, Murdaugh, \& Parsons, 2002). Physical activity is also considered to be helpful in reducing anxiety and depression, enhancing self-esteem, and managing stress (Berger, Pargman, \& Weinberg, 2006). Physical activity can also serve as an approach to socialization; it can increase an individual's capacity to interact with social groups (Milroy, 2010). 
INTERNATIONAL STUDENTS' PHYSICAL ACTIVITY

Although numerous studies have emphasized the benefits of living an active lifestyle, sedentary lifestyle and obesity keep escalating. It was found that the number of the people who meet the physical activity guidelines is quite low comparing to the number of people who are overweight and obesity. Research suggested that only $25 \%$ of adult Americans meet the leisure time activity recommendation, nearly one-third of adults do not engage in any leisure-time physical activity (Manson, Skerrett, Greenland, \& VanItallie, 2004). WHO (2012) suggest that that the physically inactive rate within the adults aged 15 and over was $31 \%$ (men 28\% and women $34 \%)$.

Studies have conducted in college students and the similar trend was found. The National College Health Risk Behavior Survey (NCHRBS) suggested that 20.5\% of college students were overweight (Lowry, Galuska, Fulton, Wechsler, Kann, \& Collins, 2000). Suminski, Petosa, Utter, and Zhang (2002) explored different PA patterns of college students from multiple ethical backgrounds. They found $53 \%$ of women and $40.3 \%$ of men didn't engage in vigorous PA while $22 \%$ of women and $11.3 \%$ of men did not engage in any PA. A more recent investigation showed that of all the participants from two universities, $43.5 \%$ students met recommended levels of PA, $44.2 \%$ were insufficiently active, and $12.4 \%$ were inactive (Fountaine, Liguori, Mozumdar, \& Schuna, 2011).

Previous studies suggested that ethnicity is one of the determinants of PA participation. Minorities who are less active than whites have a higher rate of overweight and obesity. Suminski and colleagues (2002) explored different PA patterns within people from diverse racial backgrounds. 874 Asian, 332 African, 1101 White and 529 Hispanic American college students aged 18 to 25 years participated in this study. The program was described as a course requirement. Multiple variables related to PA (i.e., youth PA participation, current PA, and 
INTERNATIONAL STUDENTS' PHYSICAL ACTIVITY

weekly TV viewing) were measured via self-report at the beginning of spring semester, in summer and at the beginning of fall semester in a school year. Effects of gender, race, and interaction between gender and race were discussed. Regarding the race and gender, it was found that $28.1 \%$ of Asian, $23.5 \%$ of African American, $17.4 \%$ of White, and 20.3\% Hispanic women and $11.7 \%$ Asian, $7.7 \%$ African-American, $12.0 \%$ White, and 13.8\% Hispanic men did not engage in any PA. Regarding the interaction between gender and race, a significant difference of current PA and youth PA was found between men and women in Asian, White, and Hispanic groups. There was also a significant difference on current PA between African American men and women. Among all women, Asians reported the lowest level of the current and youth PA. Asian men also reported the lowest level of youth PA. This study suggested that PA promotion program should consider race. More effort should be placed on minorities. Meanwhile, PA promotion programs should address the specific needs of racial minorities. For example, in this study, both Asian men and women reported significantly lower youth PA, which suggested that they might be less informed about the importance of PA in childhood and adolescence. Thus, they might be less ready to adopt the interventions that were designed for Americans.

The similar trend was found for international students. Yoh (2008) investigated the relationship between ethnicity and PA. 512 (215 were females and 306 were males, $28.6 \%$ from Asia, 23.4\% from Europe, 17.3\% from South America, $6.7 \%$ from North America, and 14\% from Africa) international students were recruited from 5 colleges and universities in the Midwestern area. Their demographic information, time spending on PA, and frequency of PA were inquired through a questionnaire investigation. Results suggested that male international students spent more time engaging in PA than female students. Compared to the international students from other origins, students from North America (Canada and Mexico) spent the most 
INTERNATIONAL STUDENTS' PHYSICAL ACTIVITY

of time on PA. Students from Europe (e.g., England, Germany, Spain, and France), South America (e.g., Brazil, Venezuela, Argentina), and Africa (e.g., Nigeria, Republic of South Africa) participated in less PA than North American international students. Asian students (e.g., China, India, Japan, Korea, Taiwan, and Thailand) spent significantly less time comparing to all the other groups. Both male and female Asian students were less active than other racial groups. Besides PA participation, factors related to international students' PA participation were explored by several studies. Using the same sample, Yoh (2009) further explored their motivation for engaging in PA. International students reported that good health and physical condition, getting regular exercise, developing and maintaining physical functioning, developing positive mental qualities, and learning the activities that can be used outside of school were the five most important objectives. Social reasons (i.e., making new friends, networking), developing leadership, developing sportsmanship, understanding mechanical principles of movement, and effects of exercise on the human body, and developing self-realization were reported as the least important reasons.

PA participation is influenced by an individual's attitude, belief and value system. For example, Eyler and colleagues (2002) explored women's PA from diverse racial/ethnic groups by reviewing 91 articles of women participating in leisure time PA. They found that white women were more likely to engage in leisure-time PA while racial minorities (i.e., Black, Asian, American Indian, and Hispanic) were more likely to participate in occupational, transportation, and household PA. The authors also explained that this finding can be associated with the expectation of minority women's gender role. Minority women (i.e., American Indian, Asian) were expected to spend time on housework and caregiving; leisure time PA was not consistent with their identity. 
INTERNATIONAL STUDENTS' PHYSICAL ACTIVITY

The constraints from cultural beliefs and values also influence international students' PA participation. Previous studies suggested that Asian women are least active among all international students (Suminski et al., 2002; Yoh, 2008; Yan, 2012). This finding can be explained by cultural beliefs as well. Females from Eastern cultures have not been encouraged to engage in PA since it was considered as a masculine characteristic. Another explanation is that Asians placed more emphasis on academic performance; they devoted more time to education. Compared to other racial groups, Asian students might focus more on adjusting to their educational environment rather than exploring new PA opportunities during their transition. Another study also examined college students' beliefs and knowledge of PA. Haase, Steptoe, Sallis, and Wardle (2004) analyzed the prevalence of PA, economics, geography, culture, and politics in 23 counties. In this study, the authors inquired about participants' health beliefs, PA participation, knowledge of specific health benefits of PA, as well as the socioeconomic factors. Results suggested that levels of inactivity were lowest in North-Western Europe and U.S, and highest in Developing countries (e.g., Colombia, South Africa, and Venezuela). It was also found that knowledge of specific health benefits of PA was strongly associated with economic development. People from Developing countries knew less about the benefits of living an active lifestyle. Thus, international students from Developing countries might not be informed about PA as much as the students from the Developed countries, which explained that international students from those regions placed less emphasis on exercise. The economic factor also influenced the attitude and beliefs of leisure time PA. For example, in a Developing country in which manual labor remains common, inactivity was considered as a prestige. Thus, students in those countries might spend more time on their studies rather than actively seeking opportunities for leisure time PA. 
INTERNATIONAL STUDENTS' PHYSICAL ACTIVITY

Walker, Jackson, and Deng (2007) found that Chinese students perceived more interpersonal and intrapersonal constraints, while Canadian students were more likely affected by structural (e.g., available and accessible resources and facilities) constraints. This result can be partly explained by cultural difference as well. PA in China has more socializing purposes. It was also emphasized by the authors that countries of Eastern culture have traditional sports, which contained exercising, socializing, artistic, and entertaining components. Those traditional sports are from the cultural heritage, and they are valued a lot in those international students' home countries. Living in the U.S, international students do not have the opportunity to engage in traditional sports, which could be considered as an intrapersonal barrier for international students participating in physical activity.

Pan and Nigg (2011) found that the value of PA was consistent throughout three populations (Filipino, Hawaiian, and Japanese), but valued in very different ways. The top motivation of Hawaiian and Japanese participating in PA was the physical and mental benefits, while Filipino participating into PA was primarily because it can result in good appearance. Kanhan (2011) found that beliefs regarding the roles gender, religion, religiosity, and acculturation played a role in physical activity participation among Arab American. The expectations of the gender role might decrease their motivation for physical activity. Although those studies were not based on international students; it can be seen that the ethnical and cultural background affects one's PA participation.

The cross-cultural transition can be a significant barrier. Eyler and colleagues' (2002) review suggested that the higher acculturation was associated with higher PA participation. The challenge from transition is one of the biggest constraints that also impact international students' PA participation. The barriers to communication, unemployment, social alienation, and a sense 
INTERNATIONAL STUDENTS' PHYSICAL ACTIVITY

of hopelessness decreased their time and effort on recreational activities (Taylor \& Doherty, 2005). Shifman, Moss, D’Andrade, Eichel, and Forrester (2012) investigated the barriers that international students face to participate in intramural sports. 292 students (48.3\% female and 51.7\% male) enrolled in a Canadian university participated in this study. Seventy identified themselves as international students (67.1\% of them were Asians, $7.1 \%$ were Central Americans, South Americans, and Caribbeans; $15.7 \%$ were Europeans; $5.7 \%$ were North Americans, and 4.2\% were Africans) while 222 were domestic students. Their PA participation, preferences, and perceived barriers were measured using a 5-point Likert Scale. Results suggested that no one to participate with, lack of time due to work, reasons related to family or school, and high selfconscious due to PA participation were the greatest constraints for international students to participate in intramural sports. Due to the discrepancy in the sample size between international and non-international students, the independent T-test did not reveal any significant difference in the perceived barriers between the two groups.

Li and Stodolska (2006) interviewed 16 graduate students (eight male and eight female aged from 25 to 40) originally from China to explore how transition influenced their participation in leisure activity. Participants were selected through purposeful and theoretical sampling. All the interviews were conducted in Chinese. All participants' daily leisure time activity, barriers to participating in leisure time activities, and their transition experiences were inquired. Interviews were translated by the first author and checked by two people fluent in both English and Chinese. It was found that Chinese students perceived leisure time activity as an approach for relaxation. They had the desire to engage in meaningful leisure activity (not just PA). However, demands and pressure from academics left them limited time to engage in leisure time activity. Chinese students placed more importance on education compared with other daily 
INTERNATIONAL STUDENTS' PHYSICAL ACTIVITY

activities. Leisure time activity was associated with a sense of guilt unless those activities offered them opportunities to improve English.

\section{Promoting Physical Activity within College Students: Applying the Interventions to International Students?}

Previous studies suggested that physical activity can be a useful tool for international students to facilitate the transition and maintaining their cultural identity (Allen, Drane, Byon, \& Mohn, 2010). Currently, international students' participation in PA is lower than domestic students (Yan, \& Cardinal, 2013). Developing interventions to engage more international students in PA can be beneficial on multiple levels, including improved physical and mental health, socialization, assistance with transition and adjustment, and maintaining cultural identity. Currently, there is no study conducted to promote PA in international students.

Intervention programs to promote PA and healthy behaviors were developed in college students. Researchers can benefit from PA intervention within college students due to the similar physical environment that they share with international students. College is a unique time where people are going through the essential developmental stages cognitively, emotionally, and psychologically. University environment is also considered as a different administrative structure (Milroy, 2010). Factors influencing college students' PA participation can be important for international students, as well. Keating, Guan, Piñero, and Bridges (2005) published a metaanalysis regarding college students exercising behaviors. They found that more college students adopted a sedentary lifestyle. Compared with other populations, college students' overall PA was not higher. It was suggested that college students' PA pattern was different. They were more likely to engage in PA during work days rather than the weekends. College students prefer different PA compared to other adults. For example, walking was not a favorite activity among 
INTERNATIONAL STUDENTS' PHYSICAL ACTIVITY

college students, and they prefer the activities that involve in the competition. This review also explored determinants of PA. It was found that personal factors (e.g., age, gender ethnicity, PA history, health status, and duration in college), social factors (support from family and friends), cognitive factors (self-efficacy, perceived enjoyment, motivation), and environmental factors (available facilities, transportation, climate, and safety) all affected college students' PA participation. Milroy (2010) summarized PA determinants in his dissertation. There were similar determinants compared with normal adults, such as age, ethnicity, social support, and selfefficacy. However, there were also unique factors within college students due to their residing on campus. First, college students had accessible recreation facilities. Secondly, campuses located amidst a city environment with fewer sidewalks and trails negatively influenced college students' PA. Being single was positively associated with greater PA. Lastly, undergraduate students engaged in more PA than graduate students.

Milroy (2010) also summarized the outcomes of intervention studies in his dissertation. 14 studies (from 1999-2008) were identified as experimental research. Those studies measured self-report PA, and nine of them reported improved PA engagement after intervention. Pre-Post test and intervention/control design were applied in those studies. Five of them reported the effect size. It was found that the effect sizes varied from small (<.30) to medium or large (.36 to .50). The majority of them were small. However, it should be noted that all those intervention studies were based on non-college population.

The present author examined the studies that employed experimental design to promote PA participation in college students in past five years (from 2010-2014). 14 experimental studies (pre-post, or pre-post-follow-up with intervention and control group) were identified from PubMed database. Interventions were delivered in three ways: the internet, group activity, and 
INTERNATIONAL STUDENTS’ PHYSICAL ACTIVITY

on-campus class. All 14 studies reported positive changes; effect size varies from low to high.

Education about healthy lifestyle and building motivation were the major part of the intervention.

All three ways were found to be beneficial. Web-based interventions impacted a large population (e.g., large sample size from multiple universities). The intervention programs delivered through a course (with lecture and assignment) usually had a low dropping rate. Group activity (or group counseling) could offer tailored intervention addressing particular challenges (i.e. emotion, motivation, and rewarding) and needs that students encounter. The group counseling intervention also had lower drop rate as well. Two of those studies did not include a control group. Three studies were not randomly designed. In those intervention programs, promoting PA within college students was not the only objective of the program. Other issues were also involved, such as helping with eating disorders, facilitating freshmen to form healthy lifestyles, reducing obesity, and providing support (e.g. social support, improving self-efficacy and self-regulation, dealing with emotional difficulties). Motivational interviewing, social cognitive theory, CBT were used to guide the intervention designs.

Although interventions applied within college students revealed multiple levels of effectiveness. It is questionable to implement those interventions to international students. International students are a heterogeneous population due to their different cultural backgrounds. They have different native languages, traditions, cultural beliefs, and values. First of all, to work with international students, overcoming the language barrier can contribute to effectiveness. An intervention program developed in Singapore was delivered in four languages to reduce the possibility of misunderstanding (WHO, 2012). Designing an intervention program that is only delivered in English might reduce the possible benefits. Secondly, WHO (2012) suggested that intervention needs to be culturally sensitive. A culturally sensitive atmosphere can help 
INTERNATIONAL STUDENTS' PHYSICAL ACTIVITY

international students socialize and address their issues (Carr, Koyama, \& Thiagarajan, 2003).

For example, physical activity promotion programs based on college students in U.S. use group sessions (Stice, Rohde, Shaw, \& Marti, 2012), individual interview, and one on one intervention (Martens, Buscemi, Smith, \& Murphy, 2012). Those interventions might not be effective to international students whose native culture encourage less direct communication and has "facesaving” considerations (Hughes, 2004).

Based on the discussions above, more research needs to be conducted to lay the foundation for designing intervention programs within international students. 
INTERNATIONAL STUDENTS' PHYSICAL ACTIVITY

\section{Reference}

Andrade, M. S. (2006). International students in English-speaking universities Adjustment factors. Journal of Research in International Education, 5(2), 131-154.

Allen, J. T., Drane, D. D., Byon, K. K., \& Mohn, R. S. (2010). Sport as a vehicle for socialization and maintenance of cultural identity: international students attending American universities. Sport Management Review, 13, 421-434.

Berger, B. G., Pargman, D., \& Weinberg, R. S. (2006). Foundations of exercise psychology. Bowling Green State University, Fitness Information Technologies: Morgantown, WV.

Berry, J. W. (1997). Immigration, acculturation, and adaptation. Applied Psychology, 46(1), 534.

Berry, J. W. (1970). Marginality, stress and ethnic identification in an acculturated Aboriginal community. Journal of Cross-Cultural Psychology, 1(3), 239-252.

Berry, J. W. (1980). Social and cultural change. Handbook of cross-cultural psychology, 5, 211279.

Berry, J. W. (2005). Acculturation: Living successfully in two cultures. International Journal of Intercultural Relations, 29, 697-712.

Berry, J. W., \& Kim, U. (1988). Acculturation and mental health. Newbury Park: Sage.

Bradley, G. (2000). Responding effectively to the mental health needs of international Students. Higher Education 39: 417-433

Carr, J., Koyama, M., \& Thiagarajan, M. (2003). A women's support group for Asian international students. Journal of American College Health, 52(3), 131-134.

Chen, C. P. (1999). Common stressor amongst international students: Research and counseling implications. Journal of College Counseling, 2, 49-67. 
INTERNATIONAL STUDENTS' PHYSICAL ACTIVITY

Dao, T. K., Lee, D., \& Chang. (2007). Acculturation level, perceived English fluency, perceived social support level, and depression among Taiwanese international students. College Student Journal, 41(2), 287.

Dishman, R. K., Washburn, R. A., \& Heath, G. W. (2004). Physical Activity Epidemiology. Champaign, IL: Human Kinetics.

Duanmu, J. L., Li, G., \& Chen, W. (2009). Determinants of international students' academic performance: A comparison between Chinese and other international students. Journal of Studies in International Education. 14(4), 389-405.

Erikson, E.H. (1963). Childhood and Society. (2nd ed.). New York: Norton.

Eyler, A. E., Wilcox, S., Matson-Koffman, D., Evenson, K. R., Sanderson, B., Thompson, J., \& Rohm-Young, D. (2002). Correlates of physical activity among women from diverse racial/ethnic groups. Journal of women's health \& gender-based medicine, 11(3), 239253.

Finch, B. K., \& Vega, W. A. (2003). Acculturation stress, social support, and self-rated health among Latinos in California. Journal of immigrant health, 5(3), 109-117.

Fountaine, C, J., Liguori, G, A., Mozumdar, A., Schuna, J. M. (2011). Physical Activity and Screen Time Sedentary Behaviors in College Students. International Journal of Exercise Science, 4(2), 102-112.

Furndham. A. \& Bochner. S. (1986). Culture shock: Psychological reactions to unfamiliar environment. London: Methuen.

Gordon, M. M. (1964). Assimilation in American life: The role of race, religion and national origins. Oxford University Press. 
INTERNATIONAL STUDENTS' PHYSICAL ACTIVITY

Graves, T. (1967). Psychological acculturation in a tri-ethnic community. South-Western Journal of Anthropology, 23, 337-350.

Haase, A., Steptoe, A., Sallis, J. F., \& Wardle, J. (2004) Leisure time physical activity in university students from 23 countries: associations with health beliefs, risk awareness and national economic development. Preventive Medicine 39, 182-190.

Han, X., Han, X., Luo, Q., Jacobs, S., \& Jean-Baptiste, M. (2013). Report of a mental health survey among Chinese international students at Yale University. Journal of American College Health, 61(1), 1-8.

Hayes, R. L., \& Lin, H. R. (1994). Coming to America: Developing social support systems for international students. Journal of Multicultural Counseling and Development, 22, 7-16.

Hughes, H. (2004). Researching the experience of international students. In P. A Danaher, C. Macpherson, \& F. Nouwens, D. Orr (Eds.), Lifelong learning: Whose responsibility and what is your contribution? Refereed papers from the 3rd International Lifelong Learning Conference, Rockhampton: Central Queensland University Press, pp. 168-174.

Institute of International Education. (2013). Open Doors. Retrieved on December 9, 2012 from http://www.iie.org/en/Research-and-Publications/Open-Doors

Kahan, D. (2011). Arab American college students' physical activity and body composition. Research Quarterly for Exercise and Sport, 82(1), 118-128

Keating, X. D., Guan, J., Piñero, J. C., \& Bridges, D. M. (2005). A meta-analysis of college students' physical activity behaviors. Journal of American college health, 54(2), 116-126.

Kim, H. Y. (2011). International graduate students' difficulties: Graduate classes as a community of practices. Teaching in Higher Education, 16(3), 281-292. 
INTERNATIONAL STUDENTS' PHYSICAL ACTIVITY

Klineberg, O., \& Hull, F. W. (1979). At a foreign university: An international study of adaptation and coping.

Lazarus. R.S. \& Folkman. S. (1984). Stress, appraisal and coping. New York: Springer.

Lee, J., Koeske, G. F., \& Scales, E. (2004). Social support buffering of acculturative stress: a study of mental health symptoms among Korean international students. International Journal of Intercultural Relations, 28, 399-414.

Li, M. Z., \& Stodolska, M. (2006). Transnationalism, leisure, and Chinese graduate students in the United States. Leisure Sciences, 28, 39-55

Lopez-Class, M., Castro, F. G., \& Ramirez, A. G. (2011). Conceptions of acculturation: A review and statement of critical issues. Social science \& medicine, 72(9), 1555-1562.

Lowry, R., Galuska, D.A., Fulton, J. E., Wechsler, H., Kann, L., \& Collins, J. L. (2000). Physical activity, food choice, and weight management goals and practices among US college students. American Journal of Preventive Medicine, 18(1), 18-27.

Manson, J. E., Skerrett, P. J., Greenland, P., \& VanItallie, T. B. (2004). The escalating pandemics of obesity and sedentary lifestyle: a call to action for clinicians. Arch Intern Med, 164, 249-258.

Martens, M. P., Buscemi, J., Smith, A. E., \& Murphy, J. G. (2012). The short-term efficacy of a brief motivational intervention designed to increase physical activity among college students. Journal of physical activity \& health, 9(4), 525.

McLachlan, D., \& Justice, J. (2009). A grounded theory of international student well-being. Journal of Theory Construction \& Testing, 13, 27-32. 
INTERNATIONAL STUDENTS' PHYSICAL ACTIVITY

Milroy, J. J. (2010). Behavior, theory and practice: Promoting physical activity among American college students. (Unpublished doctoral dissertation). The University of North Carolina at Greensboro.

Misra, R., \& Castillo, L. G. (2004). Academic stress among college students: Comparison of American and international students. International Journal of Stress Management, 11(2), 132.

Mori, S. C. (2000). Addressing the mental health concerns of international students. Journal of Counseling \& Development, 78(2), 137-144.

Pan, J., \& Nigg, C. (2011). Motivation for physical activity among Hawaiian, Japanese, and Filipino university students in Hawaii. Journal of Applied Sport Psychology. 23, 1-15.

Pender, N. J., Bar-Or, O., Wilk, B., \& Mitchell, S. (2002). Self-efficacy and perceived exertion of girls during exercise. Nursing Research, 51, 86-91.

Ramsay, S., Barker, M., \& Jones, E. (1999). Academic Adjustment and Learning Processes: a comparison of international and local students in first-year university. Higher Education Research \& Development, 18(1), 129-144.

Redfield, R., Linton, R., \& Herskovits, M. J. (1936). Memorandum for the study of acculturation. American anthropologist, 38(1), 149-152.

Russell, J., Thomson, G., \& Rosenthal, D. (2008). International student use of university health and counselling services. Higher Education, 56(1), 59-75.

Salant, T., \& Lauderdale, D, S. (2003). Measuring culture: a critical review of acculturation and health in Asian immigrant populations. Social Science \& Medicine. 57, 71-90.

Sam, D. L. (2001). Satisfaction with life among international students: An exploratory study. Social indicators research, 53(3), 315-337. 
INTERNATIONAL STUDENTS' PHYSICAL ACTIVITY

Sawir, E., Marginson, S., Deumert, A., Nyland, C., \& Ramia., G. (2008). Loneliness and International Students: An Australian Study. Journal of Studies in International Education, 12(2), 148-180

Sherry, M., Thomas, P., \& Chui, W. H. (2010). International students: A vulnerable student population. Higher Education, 60, 33-46.

Shifman, R., Moss, K., D’Andrade, G., Eichel, J., \& Forrester, S. (2012). A comparison of constraints to participation in intramural sports between international and noninternational students. Recreational Sports Journal, 36(1), 2-17.

Stice, E., Rohde, P., Shaw, H., \& Marti, C. N. (2012). Efficacy trial of a selective prevention program targeting both eating disorder symptoms and unhealthy weight gain among female college students. Journal of consulting and clinical psychology, 80(1), 164-170.

Suminski, R. R., Petosa, R., Utter, A. C., \& Zhang, J. J. (2002). Physical activity among ethnically diverse college students. Journal of American College Health, 51(2), 75-80.

Taylor, T., \& Doherty, A. (2005). Adolescent sport, recreation and physical education: experiences of recent arrivals to Canada. Sport Education and Society, 10, 211-238.

Thomas, K., \& Althen, G. (1989). Counseling foreign students. Counseling across cultures, 3, 205-241.

Trice, A. G. (2007). Faculty perspectives regarding graduate international students' isolation from host national students. International Education Journal, 8(1), 108-117

Walker, G. J., Jackson, E. L., \& Deng, J. (2007). Culture and leisure constraints: A comparison of Canadian and mainland Chinese university students. Journal of Leisure Research, 39, $567-590$ 
INTERNATIONAL STUDENTS' PHYSICAL ACTIVITY

Wang, J. (2003). A study of the adjustment of international graduate students at American universities, including both resilience characteristics and traditional background factors. (Unpublished doctoral dissertation). Florida State University.

Warburton, D. E., Nicol, C. W., \& Bredin, S. S. (2006). Health benefits of physical activity: The evidence. Canadian medical association journal, 174(6), 801-809.

Yan, Z. (2012). Physical activity among Chinese international students in American higher education: From quantitative and qualitative perspectives. (Unpublished doctoral dissertation). Oregon State University.

Yan, Z., \& Cardinal, B. J. (2013). Promoting physical activity among international students in higher education: A peer-education approach. Journal of Physical Education, Recreation \& Dance, 84(1), 35-40.

Yoh, T., Yang, H., \& Gordon, B. (2008). Status of participation in physical activity among international students attending colleges and universities in the United States. College Student Journal, 42(4), 1110-1117.

Yoh, T. (2009). Motivational Attitudes toward participating in physical activity among international students attending colleges in the United States. College Student Journal, 43 (3), 931-936.

Zhou, Y., Jindal-Snape, D., Topping, K., \& Todman, J. (2008). Theoretical models of culture shock and adaptation in international students in higher education. Studies in Higher Education, 33(1), 63-75. 